\title{
PINTURA RUPESTRE ESQUEMÁTICA: EL PANEL, ESPACIO SOCIAL
}

\author{
SCHEMATIC ROCK PAINTING: THE PANEL, SOCIAL SPACE
}

\author{
JULIÁN MARTÍNEZ GARCÍA (*)
}

La prehistoria no puede contentarse con una humanidad abstracta

(V. Gordon Childe, 1935)

\section{RESUMEN}

El panel, utilizado para soportar los símbolos de una determinada formación social, es obvio que se convierte en un espacio de representación de la misma. Se aprovecha para incorporar, ordenar o desordenar los elementos que circulan en un determinado sistema. La acción social queda así reflejada en un producto de carácter simbólico. Aunque, evidentemente, esta representación social no tiene carácter exclusivo en la pintura rupestre esquemática, en las siguientes páginas intentaremos analizar cómo la organización y la configuración de este espacio, panel, tiene que ver con la propia dinámica social, informándonos sobre los diversos estadios de su recorrido, en una secuencia que se ordena bajo las coordenadas de lo que hemos denominado "espacio-tiempo social".

\begin{abstract}
The panel, which is used to support the symbols of a certain social formation, is turned into a space for the representation of this formation. It is used to incorporate or arrange or mess up the elements that circulate in a certain system. Thus, the social action is reflected in a product that is characterised by a symbolic nature. However, it is obvious that this social representation does not have an exclusive nature when dealing with the schematic rock painting. In the following pages we are going to try to analyse the relationship between the organization and configuration of this space, the panel, and the social dynamics, getting informa-
\end{abstract}

(*) Consejería de Cultura. Junta de Andalucía. Correo electrónico: julianmg@a2000.es

Recibido: 5-XI-2001; aceptado: 30-I-2002. tion from the different stages of its course, in series of sequences which are arranged by the coordinates of what we have called 'Social Spacial and Time'.

Palabras clave: Pintura rupestre. Esquemática. Organización social. Postpaleolítico.

Key words: Rock painting. Schematic. Social organization. Postpalaeolithic.

\section{INTRODUCCIÓN}

En el año 1958 aparece una obra fundamental para el futuro de la investigación del arte rupestre, Lévi-Strauss publica su Anthropologie Structurale. Seguidamente, Laming-Emperaire $(1962,1972)$ y Leroi-Gourhan $(1958,1965)$, introducen en el análisis del arte paleolítico la óptica estructuralista, sustituyendo definitivamente la visión histórico-cultural. Plantearon modelos de localización y asociación de las diferentes especies animales representadas en las cuevas del Paleolítico Superior en Europa occidental y las interpretaron como referentes a los mitos que trataban de las relaciones entre los principios femeninos y los principios masculinos. Su impacto, que podemos calificar de auténtica "revolución", presenta en la actualidad numerosos resultados y mantiene abierto un debate que se está mostrando muy enriquecedor.

Sin embargo, las aportaciones de Raphael en este sentido, anteriores a las de Leroi-Gourhan y Laming-Emperaire, quedaron relegadas y olvidadas debido al enfrentamiento teórico que plantea- 
ban contra las ideas dominantes del Abate Breuil (Chesney, 1991). Por este motivo terminaron siendo más influyentes en la esfera de la historia del arte que en la arqueología. Dado el interés y la influencia que tuvieron en los trabajos posteriores seguidamente las sintetizamos. Planteaba Raphael (1945), hace ya más de cincuenta años, que las figuras debían de ser concebidas como conjuntos coherentes sobre un dispositivo iconográfico que reflejaba la ideología del hombre paleolítico y resultaba de la realización de un programa; de modo que los animales y los signos estaban en función de relaciones espaciales, con asociaciones preferenciales o configuraciones recurrentes (1).

Pero fue la dinámica provocada por los trabajos de Leroi-Gourhan la que generó un cambio en la orientación de los estudios sobre el arte paleolítico, puesto que profundizó en el análisis estructuralista pasando de lo formal al estudio e interpretación de los significados. Gran parte de la investigación inspirada en ellos se está moviendo ya más allá de sus logros. El concepto estructuralista de sus trabajos fue el instrumento que marcó la línea de investigación más innovadora de los siguientes años (Sauvet y Wlodarczyk, 1977; Conkey, 1987, 1989). Por otra parte, la creación de un grupo de trabajo en la vecina Francia (Groupe de Réflexion sur l'Art Pariétal Paléolithique) ha posibilitado la sistematización de los objetivos y de los métodos de estudio del arte parietal paleolítico proponiendo, desde la discusión colectiva, una normalización global (GRAPP 1993) (2).

Sin embargo, la investigación del arte postpaleolítico ha sido menos productiva. Tanto el arte levantino como el esquemático quedaron atrapados en el marco normativo heredado de la arqueología histórico-cultural. La investigación del arte rupestre, desarrollada sobre los fundamentos de la arqueología, es tributaria de sus teorías y de sus métodos. Prehistoria y Arte Prehistórico han recorrido caminos similares en la Península Ibérica hasta los años 70 (Breuil, 1933-1935; Acosta, 1968). En las últimas décadas se separaron las trayectorias, la Prehistoria fue asumiendo las nuevas tendencias de la investigación, mientras que el arte rupestre postpa-

(1) No se prestó demasiada atención a las propuestas de M. Raphael, aunque no cabe duda que Laming-Emperaire utilizó ampliamente su obra.

(2) Groupe de Réflexion sur l'Art Pariétal Paléolithique: N. Aujoulat, C. Barrière, R. Bégouën, J.M. Bouvier, J. Clottes, M. Crémadès, M. Dauvois, V. Féruglio, J. Gaussen, M. Lorblanchet, Y. Martin, F. Rouzaud, D. Sacchi, G. Sauvet. leolítico no participó de las continuas transformaciones metodológicas de ésta.

Esta situación llevó al arte rupestre esquemático a quedar encasillado e infravalorado, no se consiguió avanzar en su análisis desde la rentabilidad que estaban aportando las nuevas metodologías. Bajo el dominio absoluto del positivismo y con la tendencia a primar las representaciones figuradas como "objetos", el arte esquemático se subió al pedestal de la tipología y se encerró en la urna de la cronología. Que si la Edad del Cobre, que si la del Bronce, que si del Neolítico, que si tales y tales paralelos tipológicos, empezaron a llenar las páginas de los estudios de pintura esquemática. El resultado nos ofrece dos realidades aparentemente contradictorias, por una parte, un enorme volumen de publicaciones sobre los conjuntos esquemáticos, por otra, una preocupante desproporción entre el ritmo de publicaciones y el estado de conocimiento. La consecuencia, inmediata, la ausencia de un modelo general que explique la pintura rupestre esquemática (a partir de ahora PRE).

En 1982, I. Hodder (1982a) aplica los criterios de la gramática generativa de Chomsky al estudio de los motivos decorativos representados en las calabazas de los nuba del Sudán, planteando cuáles son las palabras de ese lenguaje y las reglas gramaticales que lo organizan. Igualmente, al estudiar la cerámica neolítica holandesa, identifica una serie de jerarquías de oposiciones horizontal/vertical que finalmente interpreta (Hodder 1982b) valorando por encima de todo el análisis contextual.

Un año después, apareció una recopilación de artículos que nos mostraban un primer esfuerzo colectivo encaminado al examen de las consistencias estructurales en el marco del arte (no figurativo) y sus relaciones sociales. Desde distintas ópticas como la percepción, la cultura, la etnografía o la arqueología, se discutía la estructura del arte en diversos contextos, participando de una orientación común en la que el arte se consideraba como parte de un sistema de la cultura (Washburn, ed., 1983).

Paralelamente, en nuestro país, un trabajo de Martín de Guzmán (1983) planteaba la dificultad del discurso esquemático desde la óptica interpretativa, resumida en una aproximación y ensayo del "arte esquemático" a través de los procedimientos de la semiótica textual. Las dificultades de entender un fenómeno simbólico de la magnitud del "arte" esquemático eran evidentes y cualquier intento pasaba por una declaración explícita de los inconvenientes a los que había que enfrentarse. Sin

T. P., 59, n. ${ }^{\circ} 1,2002$ 
embargo, puso de manifiesto las posibilidades de este tipo de análisis.

Evidentemente, en este contexto, el camino abierto por Leroi-Gourhan para el arte paleolítico hacía imprescindible plantear algunas preguntas relativas a un fenómeno como el de la PRE. ¿Existía en la PRE un principio organizativo y por tanto estructural cuya identificación nos permitiera avanzar en su conocimiento? ¿El paradigma estructuralista, como alternativa, podría aportar los principios organizativos de este complejo fenómeno? Con estas preguntas de partida, y tras las limitaciones planteadas con la iconografía, desde la perspectiva del método de Panofsky (3) (Martínez García, 1981: 63-64), estudiábamos el conjunto del Peñón de la Virgen en Gilma (Nacimiento, Almería). Algunas recurrencias observadas en los paneles nos empujaron hacia el análisis de sus contenidos y sus relaciones con otros ámbitos peninsulares. Sus resultados evidenciaron referencias estructurales y la posibilidad de observar procesos de organización económica y social. Igualmente, se puso de manifiesto la naturaleza diacrónica o sincrónica del proceso con la incorporación del factor espacio. El modelo espacial tuvo como soporte el marco conceptual definido por D. Clarke (1968) y su resultado cuestionó la antigüedad de la PRE del sudeste (4). En efecto, ésta era más reciente que la del interior de Sierra Morena y el sudeste aparecía claramente como un área periférica del fenómeno esquemático (Martínez García, 1984: 79-80, Fig. 24) (Fig. 1).

Posteriormente, analizamos una serie de figuras entrelazadas de la Cueva de Los Letreros (VélezBlanco, Almería) (Martínez García, 1988), donde partiendo de su interpretación genealógica dibujamos el sistema de parentesco existente bajo su estructura, una "fotografía" que reflejaba la organización social y contribuía con ello al mantenimiento de la misma. Era evidente el potencial de información que encerraban los conjuntos esquemáticos, pero faltaba abordarlo desde una perspectiva más integradora y global, desde una unidad espacial nueva, con una escala que permitiera contrastar las propuestas. Así fue como realizamos el análisis de la PRE en la Península Ibérica, fruto del

(3) El método había sido aplicado a los grabados rupestres gallegos por Alonso del Real (1975).

(4) Desde los trabajos de Breuil, el sudeste se mantenía como el lugar de origen del arte esquemático, tanto por los paralelismos con las decoraciones de los materiales muebles documentados en las excavaciones de Siret, como por el soporte difusionista del modelo colonial.

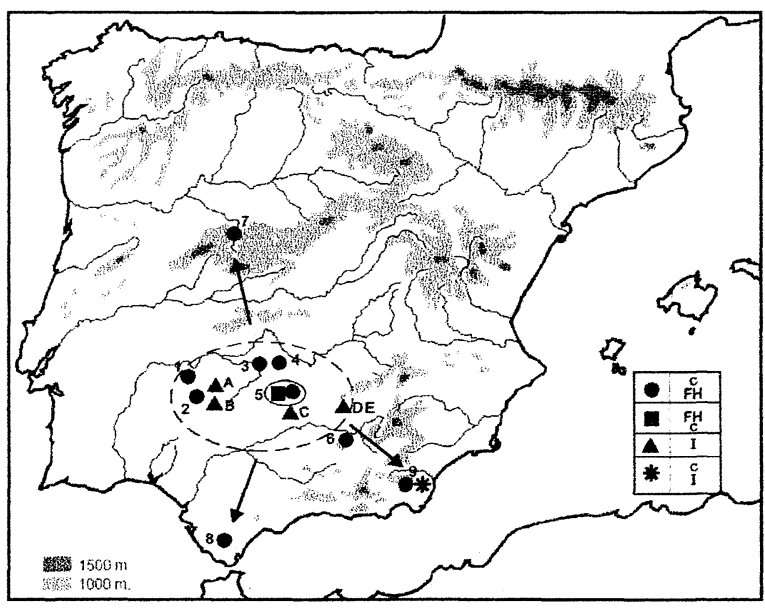

Fig. 1. Centralidad y periferia: propuesta realizada tras el análisis de las asociaciones recurrentes a partir de figuras humanas y cuadrúpedos (Martínez García, 1984: Fig. 24).

cual podemos considerar el trabajo que ahora nos ocupa (5).

\section{EL PANEL COMO ESPACIO DE REPRESENTACIÓN SOCIAL}

Es obvio que la PRE es un producto cultural más, su presencia en los abrigos será vista, por tanto, como cualquier otro aspecto de la cultura que forma parte de un sistema, como una producción social más que surge de formaciones sociales determinadas y de sus circunstancias históricas. En este sentido, sus elementos juegan un papel importante en la producción y reproducción de las relaciones sociales, colaborando tanto en la estructuración de la organización social como en el mantenimiento de la misma.

La PRE, generada por grupos humanos, fue ocupando espacios geográficos en un proceso de territorialización a lo largo del tiempo. Su distribución aporta información válida para empezar a comprender un fenómeno de "ocupación simbólica" sobre los mismos que, cada vez, se muestra más complejo y permite, a la vez, realizar una primera valoración sobre la construcción de un espacio social, entendido como territorio (Martínez García, 2000: 36-

(5) Martínez García, J. 1997: La Pintura Rupestre Esquemática en las primeras sociedades agropecuarias. Un modelo de organización en la Península Ibérica. "El panel como espacio de representación social", Cap. IV, 491-535. Universidad de Granada. Tesis doctoral inédita. 
37) (6). Es, por tanto, un producto del comportamiento social (7) y nos puede informar sobre la propia organización socio-económica.

Esta producción está compuesta por elementos pintados que pueden cambiar con el tiempo y el espacio, tanto en la forma como en el significado. Sistemas como el que nos ocupa se caracterizan porque presentan una tendencia inherente hacia la polisemia, hacia grupos de significados diferentes (8). Por este motivo no intentaremos interpretar el significado de los elementos pintados individualmente, puesto que esta significación depende de la tradición, de cómo se agrupen, del contexto donde sean usados y de las relaciones y estructuras sociales. Sin embargo, sí optaremos por poner de manifiesto que responden a un estructura lógica y que son abarcables en su organización interna, permitiendo lecturas diacrónicas y confirmando su uso repetitivo como una característica propia de la aceptación colectiva, social, que tuvieron.

Este aspecto, lo colectivo, se muestra como un factor fundamental, la aceptación de una PRE concebida como un proceso colectivo nos permitirá explorar otros niveles de análisis. En este sentido estamos de acuerdo con Jamenson (1981: 286), cuando se muestra partidario de anteponer la certeza de una hermenéutica basaba en nociones de colectividad para el arte rupestre, por encima de temas individuales y de experiencias personales. En efecto, la percepción del tiempo y el espacio es común a todos los miembros de un grupo social que participan de unas mismas condiciones de control material de la realidad (Hernando, 1999: 9).

Tras este posicionamiento, queda claro que nos

(6) Los trabajos de análisis macroespacial se han mostrado muy eficaces a la hora de ofrecer propuestas novedosas. El soporte fundamental de las mismas han sido los grabados rupestres gallegos (Bradley et al., 1993, 1994), aunque también se ha aplicado en el sur peninsular a la PRE (Martínez García 1998). Por su parte, el área de contacto entre ambos fenómenos, grabado y pintura, en el noroeste peninsular ha sido objeto de algunas propuestas bajo el marco de "frontera" (Bradley y Fábregas, 1996, 1999).

(7) D. Fiore (1996: 251) ha definido tres niveles para la conceptualización del arte rupestre como producto social: el primero referente a la construcción de imágenes visuales; el segundo, relativo a los contenidos ideológicos, tanto explícitos como implícitos y, por último, el tercero, relacionado con la organización del proceso de producción material.

(8) Dado que la PRE queda dentro de las coordenadas de un simbolismo cultural, donde la diversidad de creencias y su repetición aparecen como necesarias y presenta, al menos en parte, una orientación común para los miembros de una misma sociedad, debemos tener en cuenta una de las características compartidas por todos los fenómenos de este tipo: la ausencia de una interpretación permanente, ahistórica, ya que el campo de evocación no queda determinado. interesan más las generalidades de su conjunto, el soporte estructural que articula el "Sistema Esquemático" que las particularidades de apreciación estilística o tipológica de sus componentes (9).

Los abrigos han sido objeto bien de una única intervención o bien de acumulaciones provocadas con el paso del tiempo. Por tanto, nacidos de una sincronía total o ejecutados en cortos intervalos de tiempo. Otras veces son el resultado de la incorporación de elementos a lo largo de siglos. Atrapados entre las variables del tiempo y el espacio, los abrigos pintados nos ofrecen un marco amplio al que se va incorporando el juego normal de variantes, sustitución de unos símbolos por otros, supervivencias y decadencias.

Sin embargo, a pesar de ello resulta significativo que los paneles constituyan un universo en el que los elementos son solidarios. Son numerosos los análisis que han contribuido a fundamentar esta solidaridad (tipológicos, estilísticos, estadísticos) y otros factores como los locacionales, topográficos, etc. que la revalidan. Pero, quizás, sea la lógica interna de su estructura organizativa la que mayor coherencia aporte al "sistema esquemático".

Recordemos al respecto un trabajo sobre los petroglifos gallegos que trata la problemática de la organización interna de los paneles y cuyas propuestas se concretan en una oposición estructural entre la parte superior e inferior de los mismos. Tres estaciones atribuidas a la Edad del Bronce (Caneda, Monte Arcela y Tourón) muestran un mismo orden relativo a los motivos comunes que contienen (Santos Estévez, 1998: 84).

El abrigo pintado, al igual que un asentamiento, será considerado como la unidad de análisis, pero es el panel, como en el asentamiento sus partes (unidades domésticas, defensivas, almacenamiento, necrópolis) lo que consideramos unidad mínima de análisis (10). Esta unidad mínima estará constituida por un determinado número de elementos (figuras),

(9) Aunque indudablemente estas categorías se han mostrado como válidas para caracterizar al conjunto de productos culturales que estudiamos, sólo deben ser un medio para el análisis, no la finalidad del mismo. En otra ocasión hemos apuntado que es evidente la necesidad de describir y consiguientemente ordenar y clasificar tipológicamente las manifestaciones pintadas, pero que era obvio que éste no debía ser el objeto del estudio del «arte» prehistórico (Martínez García, 1988: 183).

(10) El panel ha sido también considerado como la primera escala de la articulación del arte rupestre gallego, aunque asociando panel y estación (Santos y Criado, 1998: 582) en una propuesta menos restrictiva que la que hacemos aquí. Por su parte, LeroiGourhan (1972: 297-298) señalaba para el arte paleolítico un concepto más complejo de panel dadas las características de las cuevas, aunque tratándose siempre de un espacio delimitado. 
que podrá oscilar de uno a $\mathrm{N}$ elementos, tantos como queden agrupados en su relación y configuración espacial.

El panel, por tanto, es un espacio limitado, de mayor o menor tamaño, pero limitado. La tendencia de todas las composiciones registradas en los abrigos compuestos con elementos del "sistema esquemático" tiende a matrices rectangulares o cuadradas, muy pocas veces descompensadąs por ángulos oblicuos, pero nunca son circulares.

Su articulación se produce a través de la composición del mismo, de sus relaciones temáticas y estructurales, en función de dos categorías generales, la de un espacio horizontal y la de un espacio vertical. Pero ¿la organización y configuración de este espacio tiene que ver con los procesos de organización social? Y si es así, ¿ cómo podemos detectarlos y explicarlos? Si la acción social es capaz de reflejarse en escalas espaciales como el territorio ¿por qué no va ocurrir lo mismo en escalas menores, como los paneles?

El desarrollo de la pintura esquemática fue largo en el tiempo, mientras que en el espacio se extendió por toda la Península Ibérica para el ámbito analítico que abarcamos (11). La dificultad de seguir su evolución interna viene determinada por la carencia de una secuencia cronológica basada en fechaciones radiocarbónicas como ocurre en los contextos arqueológicos. Aunque es evidente que se avanza en este campo con la incorporación de análisis por AMS (Chaffee et al., 1993; Watchman y Lessart, 1993; Bednarik, 1993), no contamos con ninguna referencia para los soportes parietales esquemáticos, aunque indirectamente, la presencia de los mismos elementos simbólicos en otros contextos como los megalitos o los asentamientos permiten claras correlaciones que nos acercan a su marco cronológico.

Sin embargo, el espacio de los paneles, su estructura, su contenido y composición, parece un buen marco para acercarnos a la organización social que quedó reflejada en los mismos, en una teórica secuencia que camina hacia la diferenciación social. Por tanto, si aceptamos que existe una relación estructural entre los rasgos socio-culturales y la percepción del espacio (Criado, 1993: 19) y que cada situación cultural exige un concepto de espacio coherente, que se transformará cuando cambie

(11) En este trabajo, no valoramos la localización de pinturas esquemáticas en otros contextos geográficos próximos como Francia o Italia. Además, las manifestaciones "esquemáticas" en sentido general presentan una distribución universal. ésta (Hernando, 1999: 22), podemos concluir que a través de la organización del espacio en los paneles podemos tener acceso al "Tiempo Social".

Desde los principios de composición desorganizadas con participación de elementos temáticos escasos (antropomorfos, zoomorfos, soliformes), hasta la estructurada y organizada presencia de nuevas incorporaciones al sistema esquemático (bitriangulares, cérvidos, ojos-soles, etc), crecientes en número y complejidad, parece existir un proceso que irremediablemente va ligado a la organización socioeconómica de las formaciones sociales que los realizan. Su distribución territorial, repetitiva, recurrente, garantiza su vinculación a mecanismos de mantenimiento del poder y del control social, proyectando la ideología dominante por el territorio.

Tres variables se muestran eficaces a la hora de analizar la estructura interna de los paneles, la escala (principió del tamaño), la posición (principio de posición) y la situación (principio del contexto de situación) (12). En este sentido manejaremos variables formales en el espacio del panel. En cuanto a la escala será un proceso comparativo (mayor o menor), mientras que en el ámbito posicional distinguiremos las localizaciones (izquierda/derecha, centro, arriba/abajo), para finalmente interpretar las relaciones que se definen bajo el contexto de situación de las figuras pintadas (horizontalidad, verticalidad, simetría, inversión, etc.). Este enfoque posicional (Sperber, 1978) no explica el fenómeno simbólico, pero el sistema definido por el juego de variables lo organiza en una estructura, en una disposición espacial.

Evidentemente, buscamos y ordenamos pautas estructurales y las identificamos (mayor/menor, izquierda/derecha -horizontal-, arriba/abajo -vertical-, simetría e inversión, etc.) pero parece necesario hacer también algún tipo de abstracción sobre el significado de estas pautas.

En efecto, para ello, vamos a comparar estructuras organizativas basadas en la participación de elementos pintados (antropomorfos) a los que atribuimos una misma categoría (hombre/mujer) y, por tanto, nos van a permitir movernos en determinadas entidades sociales, las que procedan. Formalmente, estas estructuras pueden ser muy específicas (antropomorfos individuales, grandes, pequeños, en grupos, alineados horizontalmente, ordenados

(12) Término introducido por Malinowsky (1972) en su estudio sobre el problema del significado de las lenguas primitivas. 


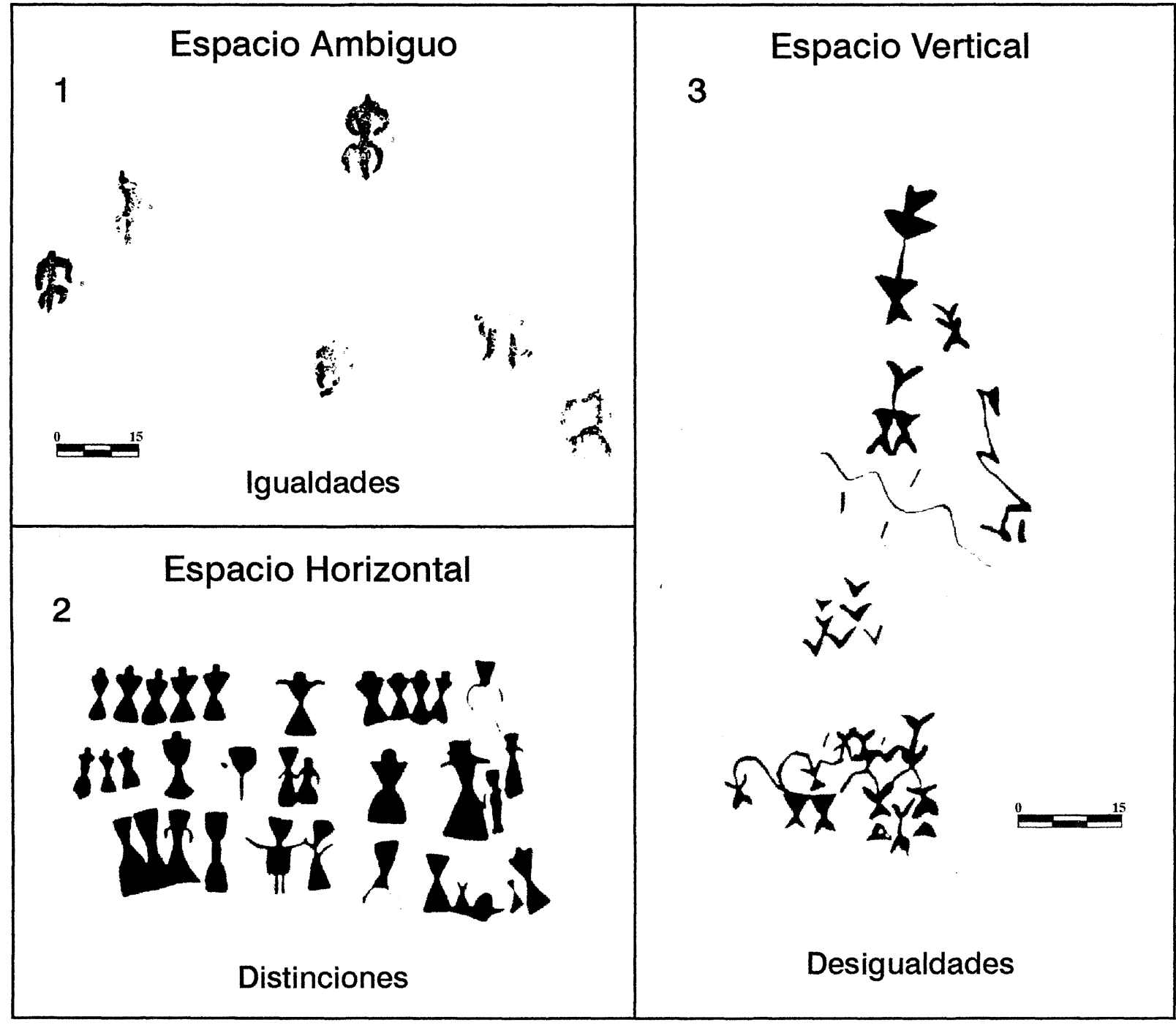

Fig. 2. Ejemplos de los tres principios generales de organización de los paneles. 1: Panel Desorganizado: Barranc de l'Infern, conjunto IV (La Vall de Laguart, Alicante). 2: Panel Horizontal: Las Viñas (Alange, Badajoz). 3: Panel Vertical: Cueva de los Letreros (Vélez-Blanco, Almería).

en verticalidad, etc.), pero es el contenido de la categoría interpretativa (individualidad, colectividad, segmentación social, distinción, jerarquía, etc.) la que tiene una significación histórica concreta, puesto que nos informa del proceso que conduce de las sociedades preclasistas a las sociedades con parámetros más complejos. ¿La PRE como elemento material de la cultura, como artefacto, fue utilizada como fiel reflejo de la realidad y nos informa de estos procesos sociales de una forma inocente? $\mathrm{O}$ por el contrario, ¿Fue la adecuación y la estrategia de una ideología que integró territorialmente y cohesionó a una formación social? Evidentemente, nos inclinamos por esta última alternativa.
Por tanto, al enfrentarnos a los paneles lo haremos caracterizándolos en una de las tres categorías siguientes:

1. Panel desorganizado: no domina ningún eje en la estructura compositiva. Un espacio carente de horizontalidad y verticalidad es un espacio ambiguo, en el que no existen diferencias, podríamos decir que refleja igualdades (Fig. 2, 1).

2. Panel horizontal: organización compositiva en función de un eje horizontal. Un espacio horizontal es un espacio no dividido, en el que las diferencias se yuxtaponen, reflejando distinciones (Fig. 2, 2).

3. Panel vertical: organización compositiva en 
función de un eje vertical. Un espacio vertical es un espacio dividido, en el que las diferencias se sobreponen, reflejando desigualdades (Fig. 2, 3).

Evidentemente, las tres dominantes de las composiciones pueden aparecer combinadas en un mismo panel, estando presentes tanto en dos como en tres de los términos. La conjunción de estos niveles de análisis, escala, composición y posición de las figuras, provoca una amplitud de disposiciones recurrentes que aparecen inmersas en un marco espacial, el panel, a las que no le es ajeno el tiempo y, por tanto, tienen un claro componente secuencial. Es decir, serán más antiguos los paneles desorganizados y más reciente la utilización del eje vertical, mientras que la dominante horizontal se muestra como un estadio intermedio. Esto es importante porque nos va a permitir establecer la secuencia relativa.

Seguidamente y bajo el análisis de estas categorías observaremos regularidades espaciales en la composición y en el contenido de los paneles, unas evidencias que nos hablan de la realidad discontinua, cambiante, repetitiva y recurrente de las prácticas sociales. Su dinámica de transmisión, muy mecánica, garantiza la continuidad estructural (13).

\section{EL SOPORTE Y LA TRADUCCIÓN DEL ESPACIO}

Seguidamente, como paso previo, consideramos la importancia que tiene el soporte físico de las paredes de los abrigos sobre el que se pintan las figuras (paneles). Basta recorrer la bibliografía tradicional para observar cómo continuamente, la totalidad de los autores ha señalado que en el estudio del arte prehistórico es necesario tener en cuenta la situación de las figuras pintadas (Breuil, 1935; Hernández Pacheco, 1959; Acosta, 1968; etc.) Sin embargo, a excepción de la propuesta de Leroi-Gourhan para el arte paleolítico, anteriormente señalada, esta premisa ha quedado sistemáticamente desconsiderada para el conjunto del arte postpaleolítico.

Se dibujan las figuras en superficies que luego se presentan como una unidad y se describen individualmente sin volver a analizar sus interrelaciones. Si la etapa interpretativa de Breuil fue superada para el arte paleolítico, en el arte esquemático ape-

(13) Ejemplos más contundentes de transmisiones mecánicas, debido a su prolongación temporal (20.000 años), son los que encontramos en las formalidades estructurales del arte paleolítico.

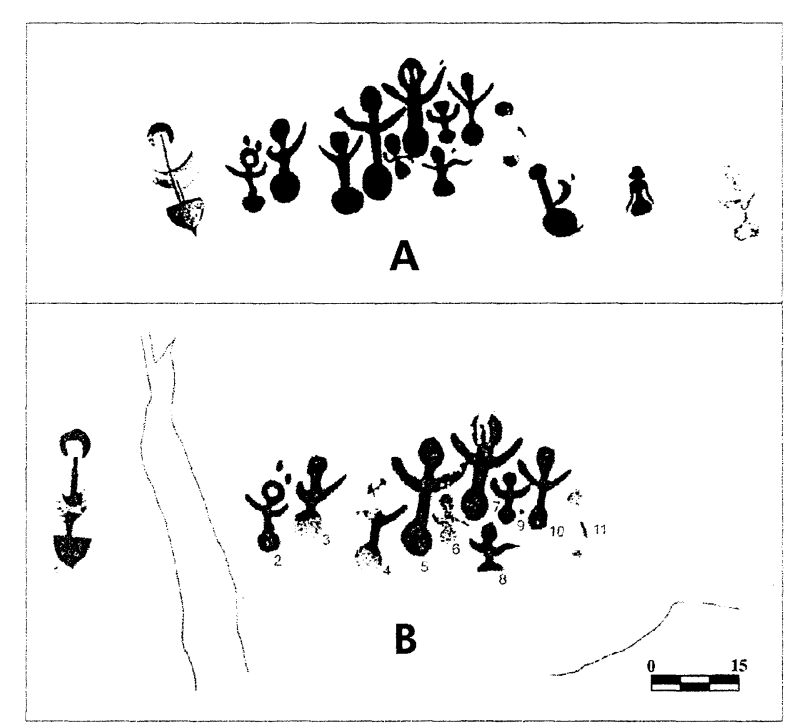

Fig. 3. La Sierrezuela (Fuencaliente, Ciudad Real). A: Conjunto presentado por Breuil (1933 III: Lám. XXXVII). B: Reproducción de Caballero Klink (1983: plano 73).

nas si se ha intentado sobrepasar el umbral de la descripción. Algunos trabajos de los años ochenta, como los de Piñón Varela (1982), para Albarracín, o los de Caballero Klink (1983), para la vertiente norte de Sierra Morena, incorporaron a los paneles pintados las anomalías del soporte como elementos de la composición. Y aunque en ningún caso se hizo referencia a su valoración como elementos de entidad espacial, el hecho de su documentación permite hoy, desde otra óptica, obtener conclusiones tanto compositivas como interpretativas. El soporte se convierte así en un delimitador de espacios, en un útil recurso espacial, que puede provocar anomalías en la propia traducción de este espacio, condicionando la distribución y relación de las figuras.

Los ejemplos son numerosos, pero sólo presentaremos dos como clara evidencia del papel que juegan las anomalías del soporte en la concepción del espacio reflejado en los paneles y por tanto en los criterios de composición y ejecución de los mismos. La primera corresponde al panel de la Sierrezuela, en Fuencaliente (Breuil, 1933 III, 79-81) y la segunda al abrigo de los Peñascales II, en el Monte Valonsadero (Gómez Barrera, 1982: 108, figs. 37 y 38). Mientras que en la primera pasa desapercibida la importancia de la anomalía, en la segunda se señala pero no se dibuja.

En efecto, en el conjunto de la Sierrezuela presentado por Breuil (1933 III, lám. XXXVII) sólo aparecen dibujadas las figuras (Fig. 3 A), mientras 


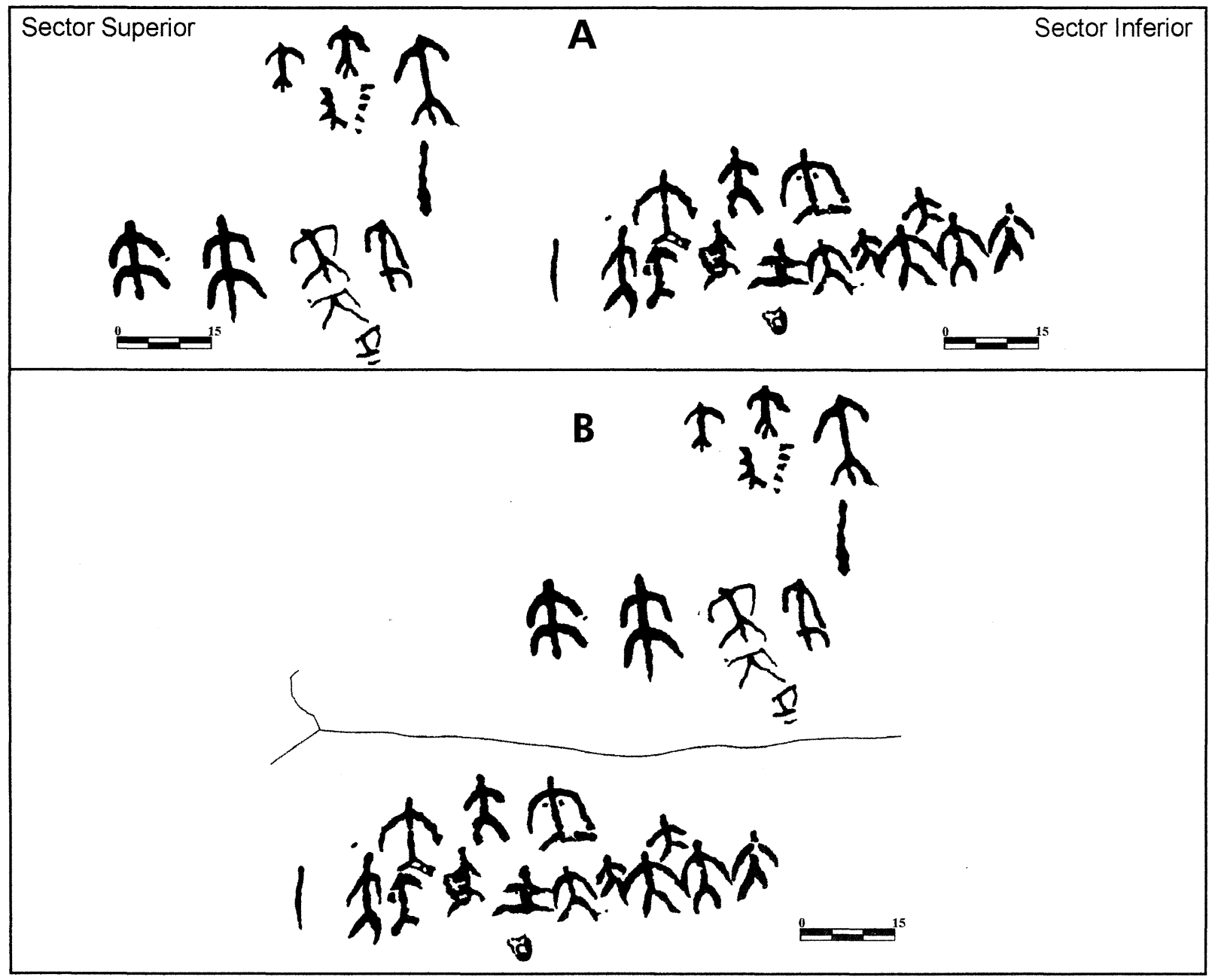

Fig. 4. Los Peñascales II. A: Según Gómez-Barrera 1982. B: El panel tal como aparece, dividido por una grieta. Montaje realizado por el autor sobre fotografía de Gómez Barrera, 1982.

que en el que reproduce Caballero Klink (1983: plano 73) se recoge la documentación de una grieta en el soporte que separa a la figura de la izquierda del resto del grupo (Fig. 3 B). Evidentemente, nos encontramos ante la separación voluntaria de dos ámbitos, el colectivo y el individual, el soporte actúa como un elemento más de la composición diferenciando y normalizando la jerarquización del espacio, independientemente de las implicaciones sociales que este procedimiento tiene y que después analizaremos en otro apartado.

En el caso del abrigo del Peñascal II, Gómez Barrera señala que aparece un gran panel dividido por una grieta (arriba con figuras masculinas, abajo con mujeres) "que parece claro le sirvió al pintor esquemático de divisoria para distribuir la escena" (Gómez Barrera, 1982: 108). Sin embargo, la repro- ducción gráfica se hace por separado (Gómez Barrera, 1982: figs. 37 y 38) (Fig. 4 A).

En su mitad superior podemos observar (Fig. 4 A) las dos láminas que nos presenta Gómez Barrera, relativas a los Peñascales II, en la parte inferior (Fig. 4 B), el montaje que hemos realizado sobre la base de la propia documentación fotográfica de la obra de Gómez Barrera, incorporando la anomalía del soporte como un elemento más (14). Evidentemente, lo que muestra el conjunto del panel es la separación de dos ámbitos en función de los sexos, una clara segmentación social que después analizaremos.

(14) Incorporamos esta nota en la versión final al haber aparecido un trabajo del mismo autor en el que sí se presenta el panel unificado (Gómez Barrera, 2001: 224, Fig. 73). 
Es obvio que el soporte delimita y provoca anomalías en la traducción del espacio, organizando la distribución de las figuras y, por tanto, desde el ámbito metodológico tiene que ser incorporado en la reproducción de los paneles, mientras que desde el marco interpretativo se debe valorar como una variable más.

\section{ESTADIOS DE ORGANIZACIÓN SOCIAL EN LA PINTURA RUPESTRE ESQUEMÁTICA}

En este apartado analizamos las regularidades observadas en el espacio del panel, no en el tiempo. Como ha señalado Criado (1993: 18) para otro ámbito de análisis, el de los yacimientos arqueológicos, por debajo de la problemática relativa a la contemporaneidad o no de un conjunto de yacimientos, conviene observar regularidades espaciales ajenas en gran medida a la cronología, la periodización, la secuencia y la fase.

Ya hemos señalado la complejidad manifiesta del "sistema esquemático", formado por una red intercomunicada de atributos y entidades que constituyen un bloque de difícil comprensión organizativa. Pero es evidente que en ese bloque radican conceptos de organización social, manejados por las formaciones sociales que los producen (pintan). En este sentido y en función de las recurrencias observadas proponemos un "viaje" por los grandes estadios que sustentan la organización de una sociedad dinámica que quedó reflejada en su propia producción material y simbólica, la PRE.

En un primer análisis hemos podido distinguir en los paneles esquemáticos al menos cuatro categorías vinculadas con la organización social. La evidencia de disimetrías sociales es obvia. La primera categoría está conectada con la aparición de distinciones colectivas basadas en el sexo y/o en la edad. La segunda se relaciona con la instauración de un ámbito de individuos colectivo y otro individual (15). En tercer lugar, aparece la configuración de un espacio "horizontal" al que se incorporan las primeras distinciones de individuos sociales y, por último, la presencia de distinciones jerárquicas que parecen indicar un proceso de desigualdad.

Antes de referirnos a los elementos sociales que

(15) Al referirnos al ámbito individual lo hacemos siempre como individuo social, dentro de un colectivo social, aunque identificable por sus atributos (posición, escala, complementos, etc.). elaboran, participan y tienen acceso a los lugares con pintura rupestre es necesario señalar algunas cuestiones que han quedado atrapadas en la bibliografía sin análisis previos. En este sentido, la autoría masculina ha sido sostenida durante más de un siglo por antropólogos y arqueólogos, manteniendo igualmente que el acceso a los lugares pintados estaba restringido a mujeres y niños. Estas limitaciones provenían "de la aplicación sin discusión ninguna de la ideología de género occidental de finales del XIX en la que ambos se consideraban secundarios en la sociedad" (Díaz-Andreu, 1999: 406). Desde la lectura de los datos reflejados en los paneles esquemáticos es difícil saber qué género participó activamente en la realización de las figuras, por lo que optaremos por la existencia de agentes sociales indeterminados, puesto que su sexo y edad se desconoce.

\subsection{Segmentaciones sociales}

Existe abundante literatura etnográfica sobre este estadio de la organización social, que muestra frecuentemente la necesidad de reforzar la solidaridad interna dentro de cada segmento mediante su institucionalización ritual, que da lugar a asociaciones restrictivas, ritos de iniciación que permiten el paso de un segmento a otro, así como la constitución de cuerpos de conocimiento de acceso restringido (Gamble, 1990).

Bajo el punto de vista de Vicent (1991: 49) el control de las reservas, en una "transición económica" (16) implica el establecimiento de divisiones entre los miembros del grupo. La forma más sencilla de hacer esto produciría, en principio, segmentos ligados entre sí por relaciones de "reciprocidad equilibrada", puesto que todos tienen derecho a participar de esas reservas, pero no "generalizadas", puesto que no todos tienen acceso directo a ellas.

En este sentido, la forma más elemental que pueden seguir las segmentaciones iniciales es la basada en el sexo y en la edad. Ambas variables generarían distancias sociales que podrían ser interpretadas como disimetrías sociales. Estas disimetrías se pudieron producir entre clases, grupos de edad y/o sexos y establecerse a nivel inter o intragrupal. Habría que apuntar que bajo la perspectiva de una diferenciación sexual como socializa-

(16) Enmarcada en la "revolución neolítica" como "revolución social”. 


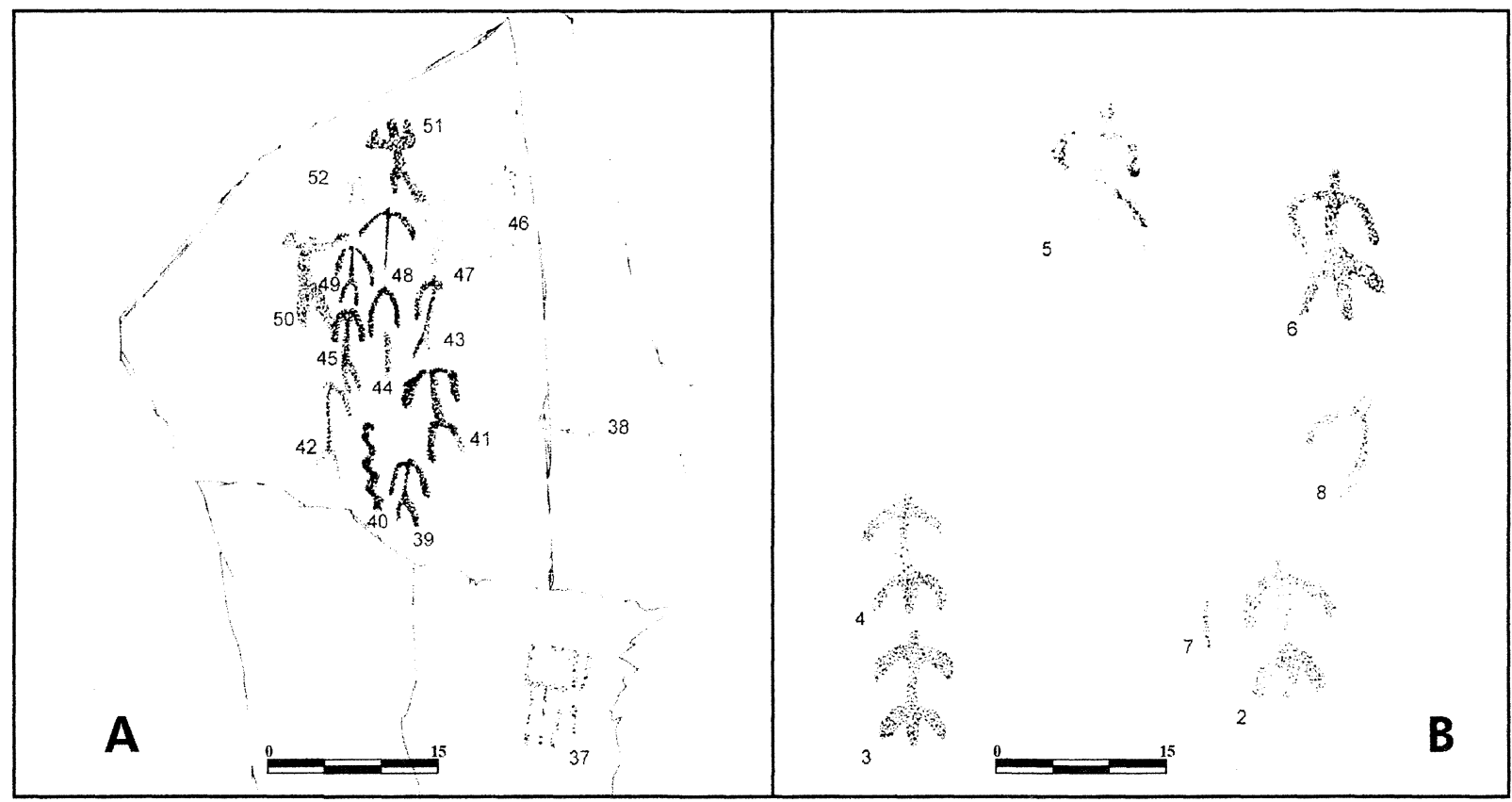

Fig. 5. Segmentaciones sociales en dos paneles del Peñón de la Virgen (Nacimiento, Almería). A: Género femenino, Peñón de la Virgen I, Grupo 10. B: Género masculino, Peñón de la Virgen III.

ción de la diferencia sexual, "ésta no es únicamente biológica, sino que también es social" (Castro et al., 1996: 36).

La documentación en los paneles esquemáticos de agrupaciones de individuos basadas en el sexo plantea de entrada la posibilidad de "leer" en ellos la existencia de segmentaciones sociales en la formación social que soporta la PRE. Pero debemos ser conscientes de las limitaciones de atribución de sexo que pueden presentar las figuras pintadas, pues posiblemente no en todos los casos fuera necesaria la identificación formal de la categoría sexual, en tanto que era comprensible bajo otros parámetros (17).

Hemos recogido algunos casos que podemos interpretar como segmentaciones sustentadas en la variable sexo, documentadas en el amplio repertorio esquemático (Figs. 5 y 6). Por ejemplo, en Gilma, encontramos en el Peñón de la Virgen I -Grupo 10-(Martínez García, 1984: 50, Fig. 9), un panel

(17) Por ejemplo, en el arte aborigen australiano, Brandl (1977: Fig. 22, 26 y 37) ha apuntado cómo los términos masculinos pueden pintarse con o sin pene, señalando que en grupos compuestos exclusivamente por varones, el pene generalmente no se muestra, mientras que en grupos mixtos puede o no pintarse (Brandl, 1977: Fig. 8, 28). Igualmente, la "masculinidad" o "feminidad" tiene otras formas de manifestarse, a través del contexto de un motivo, acompañado por artefactos propios del sexo, por convenciones estilísticas, etc. compuesto por diez figuras femeninas, que nos muestran una agrupación definida en base al sexo femenino. Se localiza en la parte alta del conjunto pintado y presenta una organización vertical en la que también participa un elemento serpentiforme (Fig. 5 A).

Solomon, al estudiar a las sociedades san de Sudáfrica en las que todos compartían el acceso a los recursos, señala que entre las cuevas que ha investigado, hay una, situada en la región sudoccidental del Cabo, con "abrumador predominio de figuras femeninas. Este insólito fenómeno, aquí y en cualquier otro lugar, sugiere que algunas oquedades podrían haber sido lugares rituales reservados para las mujeres, quizás en conexión con la iniciación femenina" (Solomon, 1997: 81-82). En este mismo sentido, investigaciones en Australia (Smith, 1991) y nuevamente en Sudáfrica (LewisWilliams y Blundell, 1998: 15) hacen posible considerar que algunos de los abrigos decorados fueran lugares rituales exclusivamente femeninos, lugares para la negociación de la identidad femenina.

Pero este tipo de agrupaciones también aparece en el caso contrario, es decir, con la asociación restringida basada en el género masculino, por ejemplo, en el Peñón de la Virgen III (Nacimiento, Almería) (Martínez García, 1984: 60, Fig. 17). Este panel aparece aislado en un frente rocoso de unos 


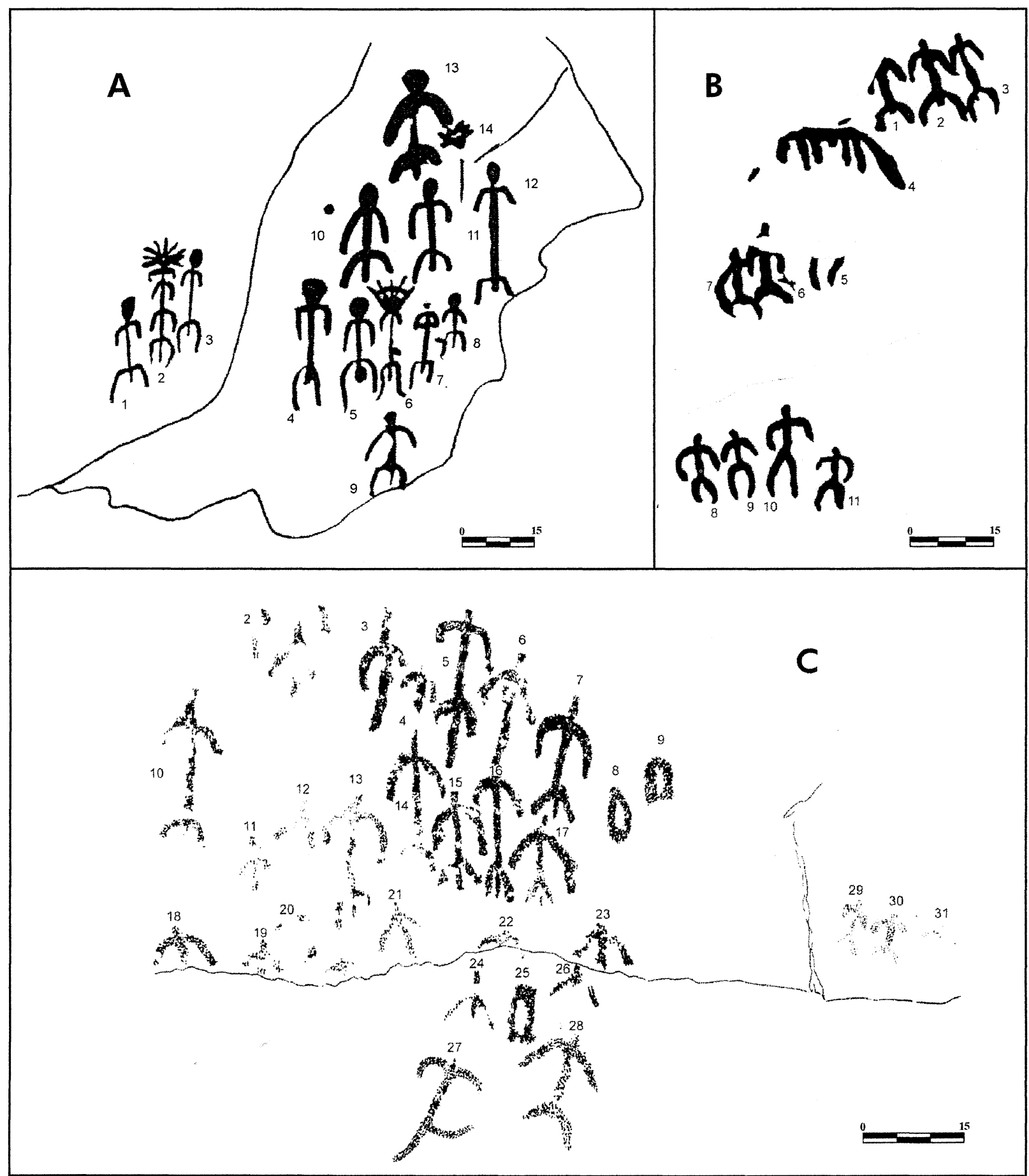

Fig. 6. Segmentaciones sociales en varios paneles. A: Castillo de Montfragüe (Torrejón el Rubio, Cáceres). B: Cueva Grande (Monte Valonsadero, Soria). C: Aljibes (Manzanares el Real, Madrid).

$14 \mathrm{~m}$ de altura y, en este caso, también se organiza en función del eje vertical (Fig. 5 B).

Es evidente que en el conjunto del Peñón de la
Virgen existen claros ejemplos de segmentaciones sociales soportadas en la diferenciación sexual, perfectamente articuladas y señaladas dentro de un 
contexto amplio de representaciones pintadas. Sus agrupaciones y, por tanto, la indicación de su unidad como categoría social es rotunda. Sin embargo, es significativo cómo esta clara diferenciación sexual, al ser contrastada con las asociaciones de otros elementos presentes en los paneles (zoomorfos -ovicápridos-) que podrían tener categoría económica, no pueden ser interpretadas como un grado diferente de acceso a los recursos (Martínez García, 1984: 70).

Un ejemplo interesante para los aspectos que nos ocupan es el localizado en el abrigo del Castillo de Montfragüe (Torrejón el Rubio, Cáceres) (Rivero de la Higuera, 1972-73). Se trata de un panel en el que se pone de relieve la segmentación social basada en términos masculinos. Es significativa la presencia de dos tonos de rojo y de dos tipos de trazo en la realización de las figuras, que posiblemente nos informan de la diacronía en la composición del mismo. Su análisis detenido, determina que nueve figuras (Fig. $6 \mathrm{~A}, \mathrm{n}^{\circ}{ }^{\circ} \mathrm{a}$ 9) podrían corresponder al primer momento, apareciendo organizadas en series horizontales y, en el centro de cada serie, una figura con la cabeza radiada, en una clara indicación de distinción individual dentro de una serie colectiva (Fig. $6 \mathrm{~A}$, n. $^{\circ} 2$ y 6 ). Con posterioridad, en un trazo más grueso y en un tono más claro de rojo, se añaden cinco figuras más (Fig. $6 \mathrm{~A}$, n. $^{\circ} 10-14$ ), cuatro de ellas antropomorfos de mayor escala, sobrepuestas sobre el conjunto existente y reorientando la organización hacia un eje vertical piramidal cuya cúspide la ocupa la figura de mayor tamaño en una posición central. Es evidente, que entre la ejecución de un grupo $\left(\mathrm{n}^{\circ}{ }^{\circ}\right.$ 1 a 9) y la del otro (n. ${ }^{\circ} 10$ a 14) se han producido cambios significativos en la organización social. Posteriormente volveremos sobre este caso.

En la misma cuenca del Tajo, en su ámbito norte, se localiza el abrigo de Los Aljibes (Priego Fernández, 1991). El abrigo I muestra un panel compuesto por 28 figuras antropomorfas, organizadas en varias filas horizontales que parecen responder a la representación de una segmentación social de carácter masculino, puesto que los escasos términos femeninos están por debajo de una grieta (Fig. 6C) y podrían ser interpretados también como una segmentación femenina, en un caso semejante al que se documenta en el conjunto de los Peñascales II.

En efecto, en la cuenca del Duero nos encontramos con varios ejemplos, de los cuales el más significativo es el que aparece en la estación de Los Peñascales II (Gómez Barrera, 1982: 109-111; figs.
37-38). Anteriormente, utilizábamos este panel para indicar la importancia de las anomalías del soporte, ahora lo haremos para subrayar la aparición de una doble segmentación basada en el sexo. En el sector superior sólo aparecen términos masculinos, mientras que en el inferior lo hacen sólo los términos femeninos (Fig. 4 B). Si observamos la figura veremos como su disposición se vuelve a efectuar sobre un eje horizontal.

Por último, estas segmentaciones también parecen estar presentes en el grupo $\mathrm{H}$ de La Cueva Grande, localizada en el mismo núcleo de Valonsadero (Gómez Barrera, 1982: 171; fig. 73). Hay tres términos masculinos, debajo un gran pectiniforme que separa a otros tres términos femeninos. Por último una grieta provoca otro espacio inferior en el que vuelven a documentarse cuatro términos femeninos (Fig. 6 B). En todos los casos las alineaciones siguen una pauta horizontal.

En función de las observaciones que hemos realizado, es evidente que la PRE refleja y transmite la existencia de segmentaciones sociales. Pero tras la identificación de estas restricciones basadas en el sexo, lo importante es señalar la implicación que tienen en la propia organización social, puesto que se socializa la diferenciación sexual y se convierte en diferencia social, diferencia que, finalmente, se traduce en disimetría social. Lógicamente, esta disimetría tiene implicaciones en las propias estrategias económicas del grupo.

\subsection{Ritos de paso}

Los ritos de paso son una de las estrategias fundamentales para la organización social. A través de ellos se ordena y cambia el "estado" de los individuos sociales. Turner (1974: 232) señala como características de los ritos de transición tres etapas: separación, liminalidad y reagrupación. Antropológicamente se ha descrito la importancia y variedad de los mismos en función de las diversas organizaciones sociales. En su desarrollo forma parte esencial el lugar, el entorno natural en el que se produce, siendo el rito de paso de adolescente/adulto uno de los más documentados. Este ritual se basa en la participación de elementos sociales adultos del mismo sexo.

Lejos de entrar a valorar su incidencia en la organización social que soporta la PRE, sí nos ha llamado la atención el contenido del panel de La Cueva en el barranco del Reloje (Anciones et al., 1993:

T. P., 59, n. ${ }^{\circ} 1,2002$ 


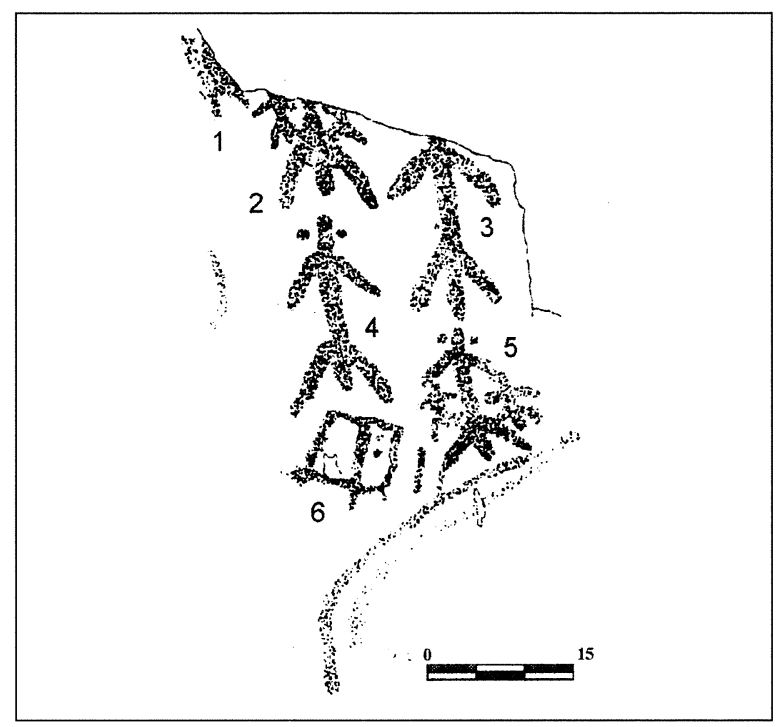

Fig. 7. Segmentaciones sociales en las que parece evidenciarse un rito de paso. La Cueva del Reloje, panel 2 (Valverde de los Arroyos, Guadalajara).

111-112). Su panel 2 aparece organizado en torno a la presencia de términos masculinos, cuatro adultos y cuatro infantiles, estos últimos asociados de dos en dos a cada adulto (Fig. 7). Este panel ratifica la segmentación social basada en el sexo, y nos aporta información complementaria sobre la existencia de pasos de iniciación al mundo de los adultos en relación con el propio sexo.

La fragmentación superior del panel impide conocer toda la composición, pero parece evidente que puede tratarse de un rito de paso. Por último, observemos en la zona inferior una figura de tendencia cuadrangular, en este caso dividida interiormente, que se convierte en un elemento recurrente en muchos de los paneles en los que se detectan segmentaciones sociales basadas en términos masculinos o femeninos, como ocurre, por ejemplo, en el Peñón de la Virgen (grupo 10) o en el abrigo I de Los Aljibes. Qué papeles juegan y qué significado tienen estos elementos geométricos en las composiciones, es algo que hoy por hoy se nos escapa, pero es obvio que forman partes significativas del conjunto y que participan en la regulación simbólica de las segmentaciones sociales.

Los ritos de paso están presentes en el contexto social que soporta la PRE y es posible que muchas de las asociaciones de individuos de un mismo sexo que se documentan en el repertorio del corpus esquemático tengan algo que ver con estas técnicas de transición social.

\section{3. Ámbito colectivo / Ámbito individual: distinciones}

Aunque ahora no analizamos la variable tiempo, es obvio que en un momento determinado, el que sea, los paneles que un principio aparecen desorganizados empiezan a mostrar tendencias recurrentes al orden y a la separación de conceptos como colectividad e individuo. Al igual que las segmentaciones sociales, este proceso quedó atrapado en la documentación pintada de los abrigos. Las transformaciones en la organización social afectan a todos los ámbitos de la cultura y el "sistema esquemático" como uno más los recoge, los refleja, los transmite, los justifica y los mantiene presentes en las estructuras sociales.

Con respecto a la separación de los ámbitos que nos ocupan se detectan varios ejemplos en el repertorio esquemático. En un apartado anterior, señalábamos cómo una anomalía del soporte separaba el ámbito colectivo del individual (La Sierrezuela y Friso de Portocarrero); pues bien, en otros casos esta separación se produce con la utilización diferencial de la escala, una para la colectividad y otra para el individuo, tal como ocurre en la Roca 2 de Callejón (Sierra de Cordoneros), en el Reboco 2 (Virgen del Castillo) o en la Covatilla de San Juan (Panel 4) (Fig. 8).

Por debajo de estos rasgos generales, se aprecian algunas diferencias tanto en la composición como en las tipologías de los elementos participantes. Sin embargo, otra recurrencia nos muestra la unidad conceptual de las mismas: en todos los casos los brazos aparecen abiertos hacia arriba (Fig. 8). Pero, por encima de cualquier particularidad, lo que todos estos paneles muestran es una "normalización" del espacio, en el que ya está claramente identificada la existencia de dos ámbitos sociales diferentes, el colectivo y el individual (18). Las composiciones aparecen fundamentadas en la separación de estos ámbitos a través de una grieta, de una fisura o simplemente de su espaciamiento, sustentadas y reforzadas por la distinta escala de los individuos y organizadas en base a una pauta de tendencia horizontal.

Su información se convierte en una referencia, en una variable más del proceso de transformaciones que se producen en el seno de la organización social y cuya direccionalidad recorre un camino que

(18) Entendido como individuo social, como ya señalábamos anteriormente. 


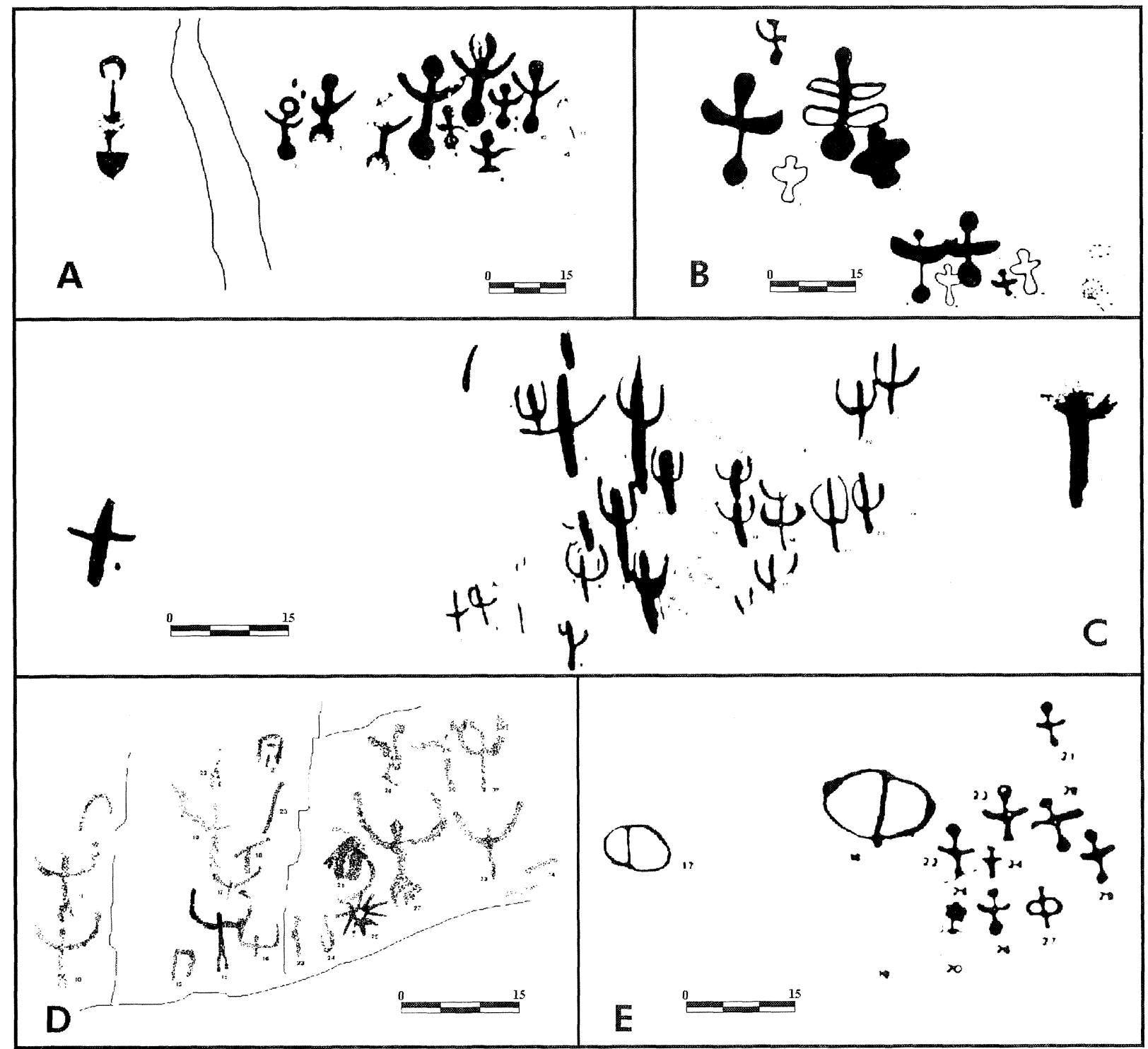

Fig. 8. Separación de los ámbitos colectivos e individual en diversos paneles. A: La Sierrezuela (Fuencaliente, Ciudad Real). B: Covatilla San Juan (Almodóvar del Campo, Ciudad Real). C: Callejón Roca 2 (Almadén, Ciudad Real). D: Portocarrero (Gérgal, Almería). E: Covatilla San Juan, panel 4 (Almodóvar del Campo, Ciudad Real).

evidencia la existencia de distinciones entre los ámbitos colectivos e individuales.

Esta horizontalidad también se puede leer, además de los casos señalados, en numerosas composiciones de antropomorfos distribuidas por los abrigos peninsulares. Seguidamente indicamos algunos a modo de ejemplo, como los del panel principal del Puerto de Malas Cabras (Breuil, 1933 II: 138, Lám XXXV: 1a), o la composición que encontramos en el abrigo del Cerro de la Oliva II, un panel con figuras agrupadas por parejas en una secuencia ho- rizontal (León Gil, 1988). En Sierra Morena Oriental vuelven a documentarse estructuras horizontales en estaciones como la Morceguilla de la Cepera, Los Guindos, Arroyo de Santo Domingo y Barranco del Bu (López y Soria, 1988: Lám. 2, 40, 61 y 77). Significativas por sus componentes antropomorfos podríamos señalar las que se localizan en la Peña del Escrito (Villar del Humo, Cuenca) (Fig. 9 A) (Breuil, 1935 IV: Fig. 33), o en el abrigo de la Hoz de Vicente (Minglanilla, Cuenca) (Martínez y Díaz, 1992: Fig. 9), donde podemos observar una 


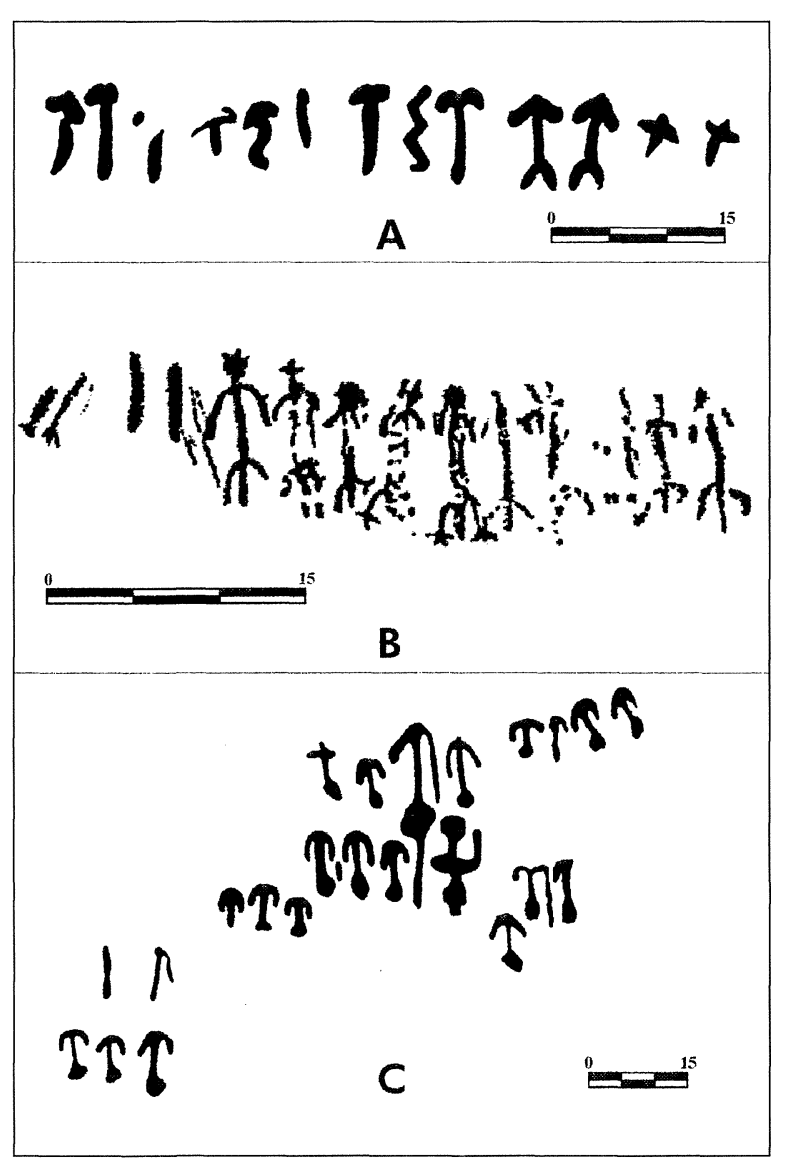

Fig. 9. Estructuras horizontales. A. Peña del Escrito (Villar del Humo, Cuenca). B. Hoz de Vicente (Minglanilla, Cuenca). C. Puntal II (La Carolina, Jaén).

serie de figuras entre las que algunas son distinguidas con atributos en la cabeza (Fig. 9 B). Por su parte, en Las Viñas (Alange, Badajoz) (Breuil, 1933: II) se documenta una agrupación de figuras bitriangulares alineadas horizontalmente, que quedan articuladas en el centro por claras distinciones (Fig. 2 B).

Por último, en el conjunto de El Puntal II (López y Soria, 1988: Lám 64), encontramos un conjunto de figuras antropomorfas alineadas horizontalmente, con utilización de escalas desiguales que generan representaciones mayores en posiciones centrales (Fig. 9 C). De la lectura de todo este conjunto de representaciones podemos plantear la existencia de un momento en el que se han dado los primeros pasos hacia la separación de los ámbitos colectivo e individual, representando no sólo sus respectivas identidades sino, también, distinguiendo individuos dentro de las series colectivas.

\subsection{El espacio jerárquico: desigualdades}

Todo este conjunto de datos, reflejando alteraciones en la concepción del espacio del panel, nos sitúa frente a unas circunstancias que denotan importantes cambios en el orden social. Seguidamente retomamos las tres categorías de caracterización que atribuíamos a los paneles con anterioridad: espacio desorganizado, espacio horizontal y espacio vertical. A través de ellos vamos a recorrer el proceso que nos lleva hacia la aparición de la jerarquía espacial en la PRE.

Veamos a continuación varios ejemplos concretos de esta utilización del espacio. Si retomamos los datos de los apartados anteriores veremos cómo las segmentaciones se organizaban en espacios horizontales. En el caso de la separación de los ámbitos colectivo/individual también domina la espacialidad horizontal.

Recuperemos ahora el ejemplo del Castillo de Monfragüe (Torrejón el Rubio, Cáceres) (Fig. 5 C), en el que hemos apuntado la ejecución de un primer grupo en series horizontales, con figuras centrales que presentan atributos en la cabeza y que como señalábamos suponen una distinción. El espacio del panel fija el tiempo, pero a la vez permite, con nuevas incorporaciones, actualizarlo. La nueva agregación de los cuatro antropomorfos del segundo momento utiliza la verticalidad, la centralidad y la mayor escala, para mostrar una nueva organización social, su posicionamiento piramidal supone ya una desigualdad frente a las distinciones anteriores y nos confirma el establecimiento de jerarquías. Este proceso de jerarquización social se ejecuta sobre un panel ya existente y, por tanto, confirma la diacronía en la ejecución del mismo, pero también la posterioridad de los agregados de carácter jerárquico, como la mayor escala y la verticalidad sobre conjuntos horizontales. Es decir, es posible plantear que las concepciones espaciales horizontales son cronológicamente más antiguas que las verticales.

Mientras que en Montfrague se ha utilizado un panel para recomponer la nuevas emergencias sociales, en otros lugares surgen, como es lógico, paneles construidos bajo el prisma de una sociedad más jerarquizada. En efecto, en numerosos ámbitos documentamos paneles totalmente estructurados, construidos bajo la presión de la verticalidad social. Por ejemplo, en San Serván (San Juan, Grieta y Hogueras II: Fig. 10 A) (León Gil, 1986: Lám. 17, 30 y 37), en Fuencaliente (Panel 1 de Batanera, Panel 4 de Escorialejo, Golondrina: Fig. 10 B, 


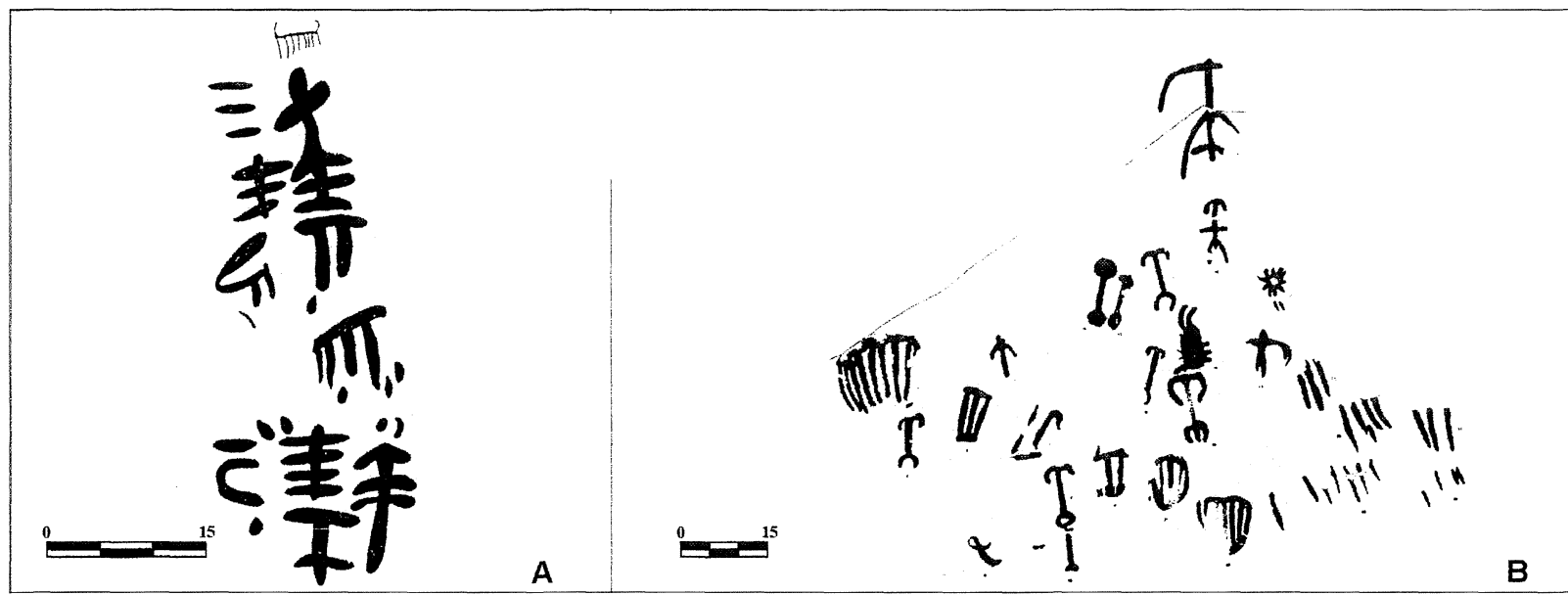

Fig. 10. Verticalidad en las composiciones espaciales, dos de los ejemplos citados. A: La Hoguera II (Arroyo de San Serván, Badajoz). B: Golondrina (Fuencaliente, Ciudad Real).

Monje) (Caballero Klink, 1983: Lám. 75, 87, 88 y 97), en Sierra Morena Oriental (Helechal) (López y Soria, 1988: Lám. 39), en el sur (Panel principal de la Cueva de los Letreros), en el norte de Alicante (Panel 7 de Penya Escrita) (Hernández et al., 1988: Fig. 379) y en la Penya del Vicari (Galiana y Torregrosa, 1995).

Como vemos, el repertorio de paneles verticales es amplio, sin embargo, en un principio y a falta de un análisis más exhaustivo, éstos se muestran minoritarios respecto a los que no presentan ninguna regularidad en la composición o aquéllos en los que domina la horizontalidad. Es evidente que a lo largo de todo el proceso de desarrollo del "sistema esquemático" se utilizaron diversas concepciones espaciales y que éstas tienen relación con la propia dinámica de las transformaciones sociales. En este sentido, la aparición de la verticalidad en la estructura de los paneles va ligada a la aparición de la jerarquía social.

\section{EL MODO DE PRODUCCIÓN BASADO EN EL PARENTESCO: LOS LETREROS}

Bajo los grandes conceptos estructurales subyacentes en la organización del espacio de los paneles, las disposiciones y asociaciones de las figuras aumentan la complejidad del sistema esquemático, mostrando interrelaciones que afectan a la organización social y a las estrategias económicas. Seguidamente analizamos una propuesta de interpretación del panel principal de Los Letreros (Vé-
lez-Blanco, Almería), uno de los ejemplos más evidentes y complejos de organización social dentro del repertorio esquemático.

No hace mucho tiempo, tuvimos oportunidad de ocuparnos del análisis del grupo de figuras entrelazadas del panel principal de este abrigo (Martínez García, 1988). Como resultado del mismo planteábamos la existencia de un sistema de parentesco. En aquella ocasión descontextualizábamos el grupo de figuras sometidas a estudio del resto del panel pintado. Evidentemente, este hecho facilitó la interpretación individualizada del mismo, pero nos privó de los datos del contexto en el que se enmarca. También entonces, apuntábamos que el estudio de sus relaciones y de sus implicaciones ampliaría la red de información y que de ello habría que ocuparse en otra ocasión (Martínez García, 1988: 184, nota 3). Seguidamente, resumimos las características del sistema de parentesco pintado en los Letreros, para después analizar la estructura del panel principal, intentando determinar algunas de las particularidades de las relaciones sociales implícitas en el mismo.

\subsection{Diagrama genealógico}

En el centro del panel principal aparece un grupo de figuras entrelazadas (Fig. 11 Superior). En la línea inferior nos encontramos cuatro figuras bitriangulares asociadas en dos díadas (Fig. 11 Superior, $n .^{\circ} 1 / 2$ y n. $\left.{ }^{\circ} 3 / 4\right)$. Sobre este conjunto se apoya una segunda línea de figuras, en la que aparecen otras dos representaciones bitriangulares (Fig. 11

T. P., 59, n. ${ }^{\circ} 1,2002$ 


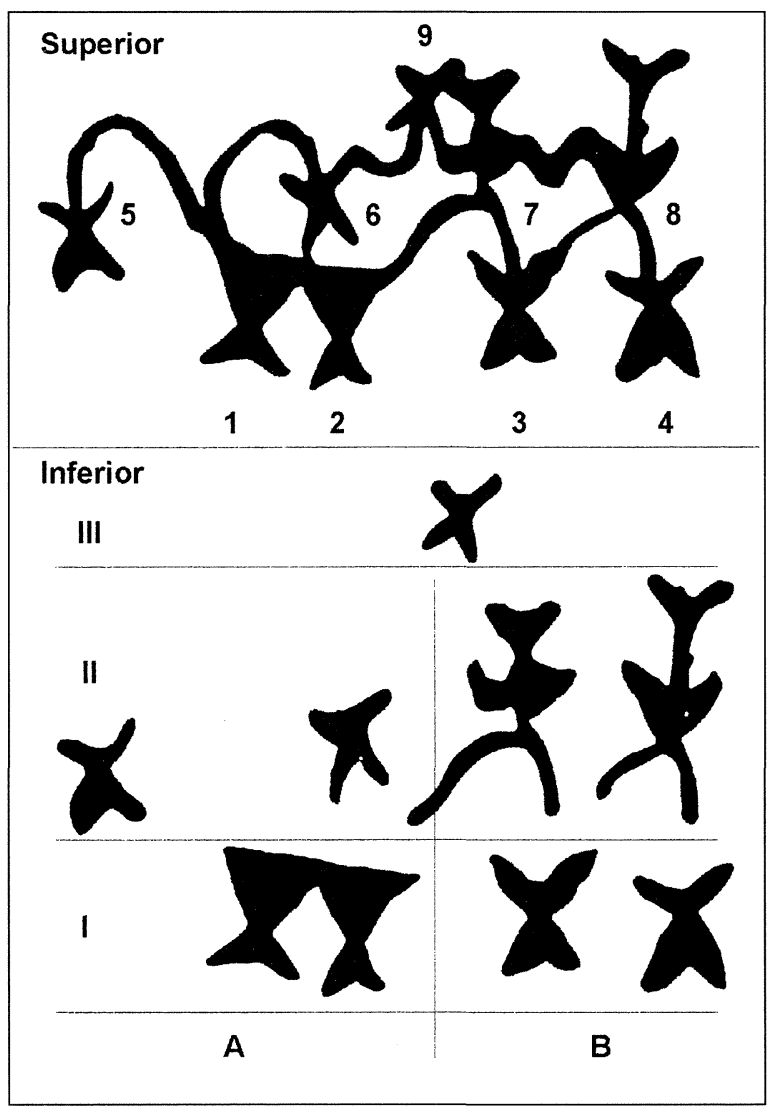

Fig. 11. Superior: diagrama genealógico de la Cueva de los Letreros (Vélez-Blanco, Almería). Inferior: descomposición del sistema en el que se muestran dos linajes (A y B) y tres generaciones (I, II y III).

Superior, n. $^{\circ} 5$ y 6 ) ligadas por dos trazos curvos a la figura 1; y dos antropomorfos (Fig. 11 Superior, n. 7 y 8). Por último, una figura más pequeña se sitúa entre la figuras 6 y 7 (Fig. 11 Superior, n. ${ }^{\circ}$ 9).

Esta composición sugirió, desde su descubrimiento, diversas matizaciones interpretativas entre las que destacamos las siguientes: "representación del árbol genealógico de una sociedad matriarcal" (Breuil, 1933-35: IV, 15-16), "rama de antepasados" (Schuster 1958) y "relación familiar" (Acosta, 1968: 82).

Frente a estas interpretaciones nos planteamos varias preguntas: ¿existía una razón para suponer la existencia de una relación entre el conjunto de figuras pintadas y algún aspecto del parentesco o de la organización social? Y en su caso, ¿se podía acceder a través de un análisis direccional a sus soportes estructurales? Aceptado que el grupo de figuras contenía y expresaba una relación genealógica, la primera evidencia que observamos es que la estructura abarcaba tres generaciones (Fig. 11 Inferior I, II y III), y que en ella quedaban representados, tan sólo, dos linajes mínimos (Fig. 11 Inferior A y B).

Pero estas respuestas sólo desencadenaban otra serie de preguntas básicas sobre los sistemas de parentesco, puesto que en todas las sociedades humanas se establecen tres tipos de relaciones familiares en la estructura del parentesco: "una relación de consanguinidad, una de alianza y una de filiación; dicho de otra manera, una relación de hermano a hermana, una relación de esposo a esposa y una relación de progenitor a hijo" (Levi-Strauss, 1958: 45), ¿podíamos indagar sobre estas relaciones en el diagrama genealógico pintado en Los Letreros? ¿Frente a qué tipo de estructura de parentesco estábamos?, y, finalmente, ¿cuál podría ser su filiación, su regla matrimonial y su pauta de residencia? A lo largo del trabajo ya citado (Martínez García, 1988) aparece desarrollado el análisis y las propuestas que nos permitieron elaborar una alternativa explicativa a todas estas preguntas. Primero, observamos que se da una relación directa entre las figuras 7 y 8 -relación Hermano/Hermana (Fig. 12 II, 1)-. Sin embargo, esta relación no se establece entre las figuras 5 y 6 , sino a través de la figura 1 -Madre (Fig. 12 I, 1)-. Luego existe una determinación de la relación consanguínea hacia el hermano materno. Segundo, queda establecida la relación esposo/esposa-figuras 6/7-a través de su hijo-figura 9-, lo cual implica también el tercer tipo de relación necesaria: progenitor/hijo (Fig. 12 II, 2). Si ahora aislamos la estructura compuesta por las figuras implicadas en los tres tipos de relación $(6,7,8$ y 9) nos encontraremos con cuatro términos: Hermano -8 , Hermana (Esposa/Madre) -7-, padre -6-e hijo/a -9-, que conforman, precisamente, la estructura elemental de los sistemas de parentesco: el avunculado (Fig. 12 III, 1).

Las conclusiones nos remitieron a un sistema de parentesco de filiación Patrilineal, organizado en base a la estructura elemental del parentesco: el Avunculado y cuya regla de residencia era Patrilocal. Por tanto, nos encontrábamos frente a grupos con creciente sentido de solidaridad, con una ideología de derechos exclusivos sobre recursos y gente, que al estructurarse en base al avunculado, les permitía un intercambio flexible de miembros entre diversas familias nucleares, generando una organización económica basada en la familia extensa. Estos grupos surgieron en contraposición a los grupos de filiación cognaticia (bandas cazadoras y 


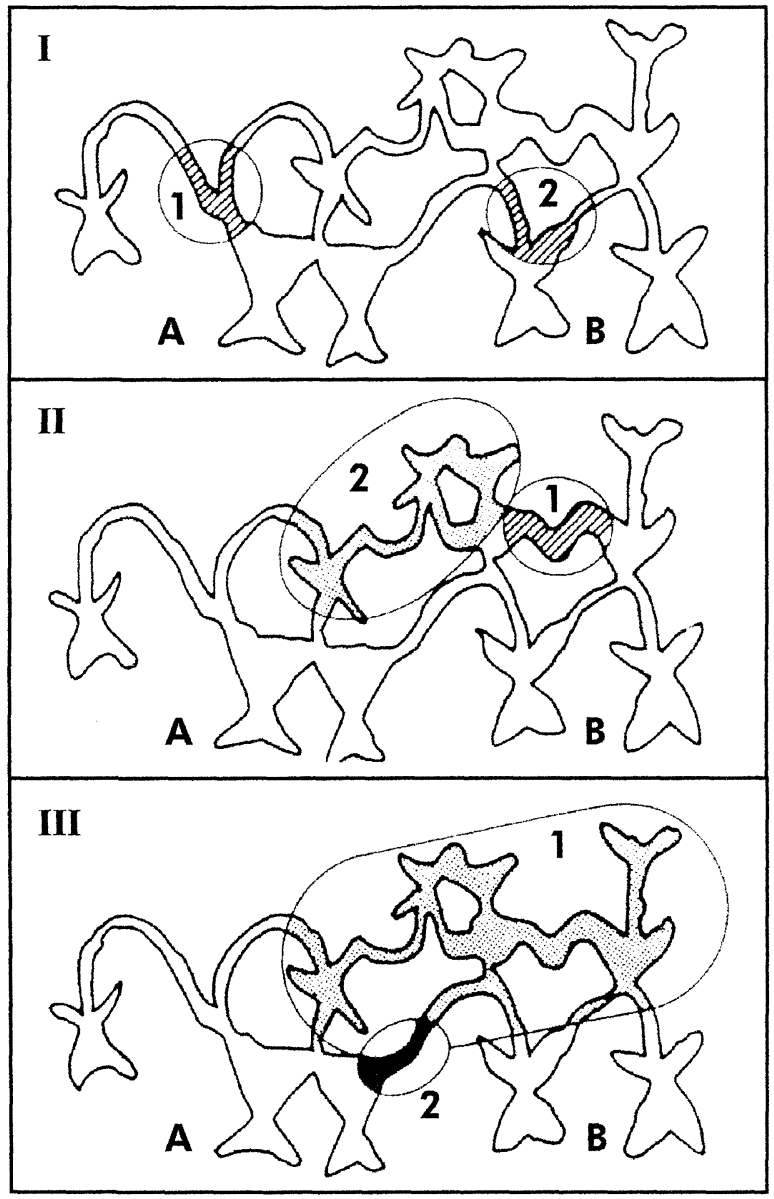

Fig. 12. Cueva de los Letreros (Vélez-Blanco, Almería). I: Determinación de los elementos femeninos del sistema. 1. Relación indirecta, a través de la Madre, de los hermanos del linaje. A. 2. Relación Hijos/Madre en el linaje B. II: Determinación de la relación consanguínea. 1. Relación directa Hermano/Hermana en el linaje B. 2. Relación directa progenitores/Hijo/a. III: Estructura elemental de parentesco. 1. Avunculado. 2. Regla de Residencia.

recolectoras) y paralelamente al desarrollo de la agricultura, respondiendo a una vida más sedentaria en poblados y a una progresiva identificación entre grupo y territorio.

Por último, valorábamos la presencia de tres figuras en la base de la generación I de uno de los linajes (linaje B) (Fig. 13, n. ${ }^{\circ}$ 10, 11 y 12), y nos hacíamos la siguientes preguntas: ¿responden a un eslabón genealógico anterior? y ¿por qué aparecen sólo en uno de los linajes?. Como respuesta, señalábamos que se podía tratar de la representación de los antepasados genealógicos que, cristalizados en una figura central con indicación del sexo, hacían

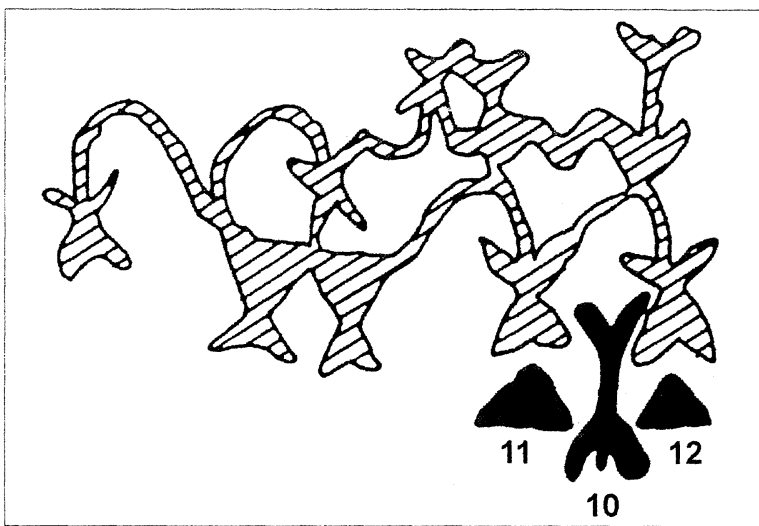

Fig. 13. Antepasados genealógicos (Cueva de los Letreros, Vélez-Blanco, Almería).

referencia al fundador del grupo, al Mito del Primer Antepasado. Mientras que su presencia, sólo en uno de los linajes, se convierte en un claro indicador de desigualdad entre los mismos (19). Pero, además, si las relaciones de linaje son la base que caracteriza la estructura de las relaciones de parentesco ¿podríamos estar frente a la imposición de procesos disimétricos en el control indirecto de los mecanismos de reproducción social? Creemos que sí. Tengamos en cuenta que la cercanía a los ancestros legitima las diferencias sociales y que, precisamente, "la transmisión hereditaria de las normas es la forma más eficaz de legitimación" (Clark, 1985: 63).

Aunque no sabemos cuándo fue efectiva la desigualdad entre los linajes y dentro de ellos, el contexto funerario de los enterramientos colectivos de Los Millares (Santa Fé de Mondujar, Almería) ya lo evidencia (Chapman, 1981), apareciendo también claros indicadores de desigualdad en determinadas sepulturas de las necrópolis centrales del Pasillo de Tabernas (Almería) (Cámara Serrano, 2000). Si como demuestran los conjuntos sepulcrales, estas diferencias ya están consolidadas hacia la segunda mitad del III milenio a.n.e., el panel de Los Letreros debe tener una cronología similar o anterior a estos momentos.

(19) Aunque en el artículo de 1988-89, también señalábamos que podía indicar la determinación del tronco común del sistema y carecer de rango, hoy nos inclinamos por reforzar la primera alternativa, interpretándolo como un claro indicador de desigualdad. Estos antepasados aparecen en el linaje que "da esposa", siendo pertinente recordar cómo en algunas organizaciones tribales el "dar esposa" es un atributo de la clase más elevada (Sahlins, 1972: 92). 


\subsection{La ampliación de la red de información}

Si ya es posible visibilizar la presencia de disimetrías sociales, enmascaradas bajo el diagrama de parentesco, la incorporación de otra serie de elementos pintados que aparecen alrededor de este conjunto, bien por encima o por debajo del mismo, nos permiten ampliar el análisis.

Por una parte, a la derecha nos encontramos con varias figuras que presentan las mismas características formales que las anteriormente señaladas (Fig. $14 \mathrm{~A}$ ). Es decir, unas figuras de las que parten líneas onduladas y en cuyos extremos se sitúan figuras más pequeñas. Como podemos advertir no están ordenadas del modo que las anteriores, bien al contrario aparecen independientes, aisladas a lo largo de un eje oblicuo. La posibilidad que ofrecen los términos 5 (linaje A) y 8 (linaje B) (Fig. 11 Superior) para generar nuevos "matrimonios" permiten ampliar la familia extensa. Pues bien, en este sentido, podríamos plantear que las figuras que hemos señalado nos informan de las posibilidades de establecer nuevas alianzas, representando alternativas para extender los lazos de parentesco y por tanto el control territorial. Se localizan por debajo del sistema de parentesco, asumiendo simbólicamente la superioridad de rango como linaje principal. Recordemos que las alianzas juegan un papel importante en la amortiguación imprescindible de los riesgos económicos (Mathers 1984) y que están encaminadas a lograr una mayor integridad territorial.

Por otro lado, en situación inferior, nos encontramos con un entramado complejo de figuras que hemos dividido en dos grupos, en función de los elementos que cada uno contiene. El primero (Fig. $14 \mathrm{~B}$ ) responde a un eje vertical en el que podemos observar la participación de figuras humanas y animales, cabras, pez, ¿ave?, así como un posible elemento vegetal. Este conjunto parece responder al ámbito económico, y podría tratarse del relato de la materialidad de la subsistencia. La apropiación de los recursos queda bajo el control de la organización social. En efecto, esta apropiación, tal y como señala Gamble (1986), no corresponde estrictamente a un problema económico, puesto que afecta a la propia organización social. De hecho, en este panel podemos observar la evidente relación de los dos ámbitos, el económico y el social. Pero además, podemos apreciar cómo la apropiación de estos recursos se hace también desde el aparato simbólico del sistema.

Inmediatamente a la izquierda (Fig. 14 C) hemos

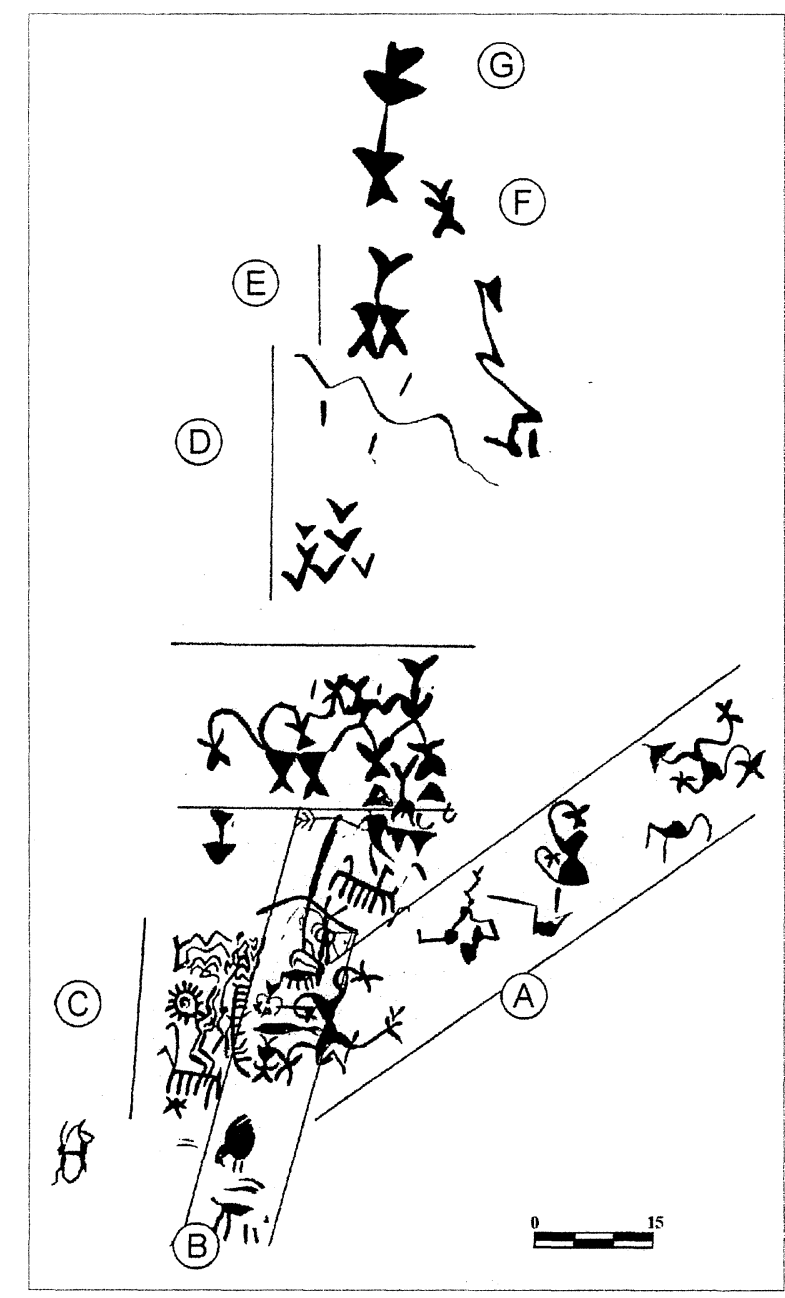

Fig. 14. Panel principal de Los Letreros (Vélez-Blanco, Almería).

distinguido otro grupo en el que aparecen los elementos cosmogónicos del sistema (soliforme, esteliforme, ondulaciones, ramiforme, antropomorfo y zoomorfo), tangenciales al relato del ámbito económico. Los recursos quedan estructurados entre la organización social y el aparato simbólico.

Ahora, analizaremos la zona alta del panel, inmediata al sistema de parentesco. Lo primero que nos llama la atención es la clara separación artificial que se produce de dos ámbitos a través de una línea ondulada bajo la que aparecen unos trazos en V (20) (Fig. 14 D). Ya hemos tenido oportunidad de ver casos en los que la separación de ámbitos se pro-

(20) Interpretados clásicamente como pájaros. En este sentido, lo que habría que destacar es que simbólicamente están por encima de la tierra. 
duce aprovechando algún recurso natural como una grieta en este panel, pero la limpieza de la superficie ha forzado el establecimiento de la separación a través del recurso de la pintura.

Inmediatamente, por encima de la línea ondulada, aparecen tres términos antropomorfos (Fig. 14 E), que nos plantean el cambio de ámbito desde la propia estructura del parentesco, de hecho mantienen una clara conexión genealógica entre ellos. Desplazado del eje de verticalidad y entre este grupo y el siguiente elemento nos encontramos con otra figura pequeña (Fig.14 F), cuya localización se puede explicar desde la perspectiva de minimizar o anular el posible conflicto previsible entre los jóvenes y los adultos o entre los jóvenes que nunca tendrán puestos de importancia. En este sentido, Wolf (1987: 122) plantea cómo la oposición entre los mayores y jóvenes y entre jóvenes y jóvenes (unos que cuando sean mayores ocuparán un puesto correspondiente y otros no) puede provocar conflictos abiertos. Igualmente está muy bien estudiada la amortiguación que provoca el sistema simbólico en este tipo de conflictos (Levi-Strauss, 1958).

Por último, está la figura superior y central, a mayor escala (Fig. $14 \mathrm{G}$ ). Centro y altura son dos lugares del espacio que comportan una connotación de poder en todos los grados, en este caso reforzada por la escala y la estructura piramidal que se desarrolla a partir de la misma como vértice.

Nos encontramos, por tanto, ante una estructura espacial culminada por una figura, que ocupa la posición central y a la vez es la de mayor tamaño del conjunto. Esta situación, que interpretamos como dominante, se representa como legítima y se utiliza para lograr que el sistema perdure, tal y como propone Godelier (1989) para otros contextos. Quizás ahora cabría preguntarse si nos encontramos ante los primeros documentos pintados que nos hablan de la aparición de las jefaturas, o si estamos ante la presencia de un líder o un jefe en los términos que expresaba Levi-Strauss (21). Es difícil responder a estas preguntas, pues si lo que caracteriza a la jefatura es la existencia de una aristocracia tribal y su carácter hereditario (Godelier, 1998, 14), también podríamos estar frente a una sociedad igualitaria en la que se manifiestan unas profundas desigualdades entre los clanes, una

(21) "Jefes" líderes que no pueden exigir obediencia entre sus seguidores, no tienen poder de coacción. Puede desembarazarse de los elementos indeseables sólo en la medida en que todos los demás piensan igual que él (Levi-Strauss, 1963: 303). sociedad en la que no hay aristocracia hereditaria, pero sí hay poderes hereditarios (Godelier, 1998: 18).

Por otra parte, el idioma de filiación y matrimonio se usa para construir linajes transgeneracionales. Permiten que los grupos reclamen privilegios con base en el parentesco, también sirven para permitir o negar el acceso a los recursos subsistenciales o críticos y organizan el intercambio de personas entre grupos con linajes establecidos. El matrimonio, como señala Wolf (1987: 120), en vez de ser una relación entre los cónyuges y entre sus parientes más cercanos, se convierte en un vínculo de alianza política entre grupos. Pero, además, al ascender la escala del parentesco desde un conjunto de relaciones interpersonales hasta el orden político, el parentesco se convierte en un elemento ideológico que gobierna la distribución del poder político.

La utilización de la PRE en la reproducción del grupo social y su organización implica a toda la comunidad, en tanto que le permite la identidad y la autoconciencia del grupo frente al exterior. Sin embargo, también pudo ser aprovechada por los representantes de algunos de los grupos sociales (clanes) en provecho suyo y de sus parientes cercanos para acceder al control coercitivo de toda la comunidad a través de la manipulación de los mecanismos ideológicos que les permiten la identificación con la comunidad/divinidad (Godelier, 1989). No podemos olvidar que la estructura social y las relaciones dentro de ella son manipuladas y tratadas conscientemente por los miembros de la sociedad, entrecruzándose con el sistema simbólico de la cultura (Wagner, 1967: 222). De hecho, el sistema simbólico basta para mantener la estructura social que media entre las personas.

Por último, señalaremos que cuando un "jefe" u otro líder se hace de seguidores merced a un buen manejo de alianzas y medidas redistributivas, llega a un punto en que "sólo se puede seguir adelante irrumpiendo por entre los límites del orden del parentesco" (Wolf, 1987: 122). La sola presencia del panel de Los Letreros nos remite a un contexto en el que se están explicitando las normas y la legítima organización social. Pero, evidentemente, también nos encontramos frente a la aparición de las primeras emergencias jerárquicas que, como acabamos de señalar, podrían estar traspasando los límites impuestos por el parentesco.

No vamos a insistir a estas alturas en la evidencia direccional de la construcción del panel. La 
composición y el orden espacial estaba determinada antes de ser pintada y respondía a la estructura social viva. No existe ningún caso, en el repertorio esquemático, tan evidente de diferenciación social. $\mathrm{Si}$ las formaciones sociales, en su proceso de jerarquización, hubiesen seguido utilizando el patrón simbólico del sistema esquemático, sería lógico pensar que este ordenamiento estructural fuese más recurrente en el repertorio de la PRE, al igual que ocurre con otra serie de paneles que podemos ver ordenados bajo otro prisma espacial. La concreción del panel de Los Letreros, formalizado en torno a la organización social descrita, nos permite utilizarlo como una referencia del "Tiempo Social-Parentesco" en la trayectoria de la PRE. En efecto, creemos que la superación del parentesco como sistema de organización social fue el motivo fundamental de la desaparición de la pintura rupestre esquemática.

\section{AGRADECIMIENTOS}

A Pedro Aguayo, que leyó las versiones previas de este trabajo y realizó valiosos comentarios y sugerencias.

\section{BIBLIOGRAFÍA}

Acosta Martínez, P. (1968): La pintura rupestre esquemática en España. Memorias del Seminario de Prehistoria y Arqueología de la Universidad de Salamanca 1, Salamanca.

Alonso del Real, C. (1975): "Intento de una iconología del arte prehistórico". Actas de las primeras Jornadas de Metodología Aplicada de las Ciencias Históricas, I. Santiago de Compostela: 93-100.

Anciones, R.; Cardito, L.M.; Ramírez, I. y Etzel, E. (1993): "Pintura esquemática en 'La Cueva' del Barranco del Reloje (Valverde de los Arroyos, Guadalajara)". Revista Wad-al-Hayara 20: 109-126.

BEDNARIK, R.G. (1993): "The direct dating of rock art". Rock Art Research 10: 48-51.

Bradley, R.; Criado, F. y Fábregas, R. (1993): "Rock art research as landscape archaeology: a pilot study in Galicia, North-wet Spain". World Archaeology 25 (3): 374-390

- (1994): "Los petroglifos como forma de apropiación del espacio. Algunos ejemplos gallegos". Trabajos de Prehistoria 51 (2): 159-168.

Bradley, R. y FÁbregas, R. (1996): "Petroglifos gallegos y arte esquemático: una propuesta de trabajo”. En A.
Querol y T. Chapa (eds.): Homenaje al profesor Manuel Fernández Miranda. Complutum Extra 6, II: 103-110.

- (1999): “La 'Ley de la Frontera': grupos rupestres galaico y esquemático y prehistoria del noroeste de la Península Ibérica". Trabajos de Prehistoria 56 (1):103114.

BRANDL, E.J. (1977): "Human stick figures in rock art". En P. Ucko (ed.): Form in Indigenous Art: Schematisation in the Art of Aboriginal Australia and Prehistoric Europe. Duckworth. London: 220-242.

Brevil, H. (1933a): Les Peintures Rupestres Schématiques de la Péninsule Ibérique II. Bassin du Guadiana. Fondation Singer-Polignac. Imprimerie de Lagny. París.

- (1933b): Les Peintures Rupestres Schématiques de la Péninsule Ibérique. III Sierra Morena. Fondation Singer-Polignac. Imprimerie de Lagny. París.

- (1935): Les Peintures Rupestres Schématiques de la Péninsule Ibérique. IV Sud-Est et Est de l'Espagne. Fondation Singer-Polignac. Imprimerie de Lagny. París.

CABAllero KLINK, A. (1983): La pintura rupestre esquemática de la vertiente septentrional de Sierra Morena (Provincia de Ciudad-Real) y su contexto arqueológico. Estudios y monografías 9. Museo de Ciudad Real. Ciudad Real.

Cámara Serrano, J.A. (2000): "Bases teóricas para el estudio del ritual funerario utilizado durante la prehistoria reciente en el sur de la Península Ibérica". $S A G V N$ TVM-PLAV 32: 97-114.

Castro, P.V.; Chapman, R.W.; Gili, S.; Lull, V.; Micó, R.; Rinuete, C. y Sanahuja, M.E. (1996): "Teoría de las prácticas sociales”. En A. Querol y T. Chapa (eds.). Homenaje al Profesor Manuel Fernández Miranda. Complutum Extra 6. II: 35-48.

Clark, G. (1985): La Identidad del Hombre. Ed. Paidos. Barcelona.

Clarke, D. (1968): Analytical Archaeology. Methuen and Co. London.

ConKey, M.W. (1987): “L'art mobilier et l'établissement de géographies sociales". L'art des objets au paleolithique 2. Les voies de la recherche. Colloque International (Foix-Le Mas-d'Azil, Nov. 1987): 163-172.

- (1989): "The structural analysis of Palaeolithic art". In C.C. Lamberg-Karlovsky (ed.): Archaeological Thought in America. Cambridge University Press. Cambridge: 135-154.

Criado Boado, F. (1993): "Límites y posibilidades de la arqueología del paisaje". SPAL 2: 9-55.

Chaffee, S.D.; Hyman, M. y Rowe, M. (1993): “AMS 14$\mathrm{C}$ dating of rock paintings". Time and Space. AURA, 8 . Ed. Steinbring, Watchman, Faulstich y Taçon. Melbourne: $67-73$.

ChAPMAN, R.W. (1981): "Los Millares y la cronología relativa de la Edad del Cobre en el Sudeste de España". Cuadernos de Prehistoria de la Universidad de Granada 6: 75-89. 
- (1991): La formación de las sociedades complejas. El sureste de la península Ibérica en el marco del mediterráneo occidental. Ed. Crítica. Barcelona.

Chesney, S. (1991): "Max Raphael's Contributions to the Study of Pehistoric Symbol Systems". En P. Bahn y A. Rosenfeld (eds.): Rock Art and Prehistory. Oxbow Monograph10. AURA Congress, Darwin 1988: 14-22.

DíAZ-ANDREU, M. (1999): "El estudio de género en el arte rupestre levantino: una asignatura pendiente". II Congrés del Neolític a la Península Ibérica. SAGVNTVMPLAV, Extra-2: 405-412.

FIORE, D. (1996): "El arte rupestre como producto complejo de procesos ideológicos y económicos: una propuesta de análisis". Espacio, Tiempo y Forma. Prehistoria y Arqueología 9: 239-259.

Galiana, M.F. y Torregrosa, P. (1995): "Las pinturas rupestres de la Penya de l'Ermita del Vicari (Altea, Alicante)". Zephyrus XLVIII: 299-315.

Gamble, C.S. (1986): "The mesolithic sandwich: ecological approaches and the archacological record of the early postglacial". En M. Zvelebil (ed.): Hunters in transition. Mesolithic societies of temperate Eurasia in their transition to farming. New Directions in Archaeology. Cambridge University Press. Cambridge: 33-42.

- (1990): "La producció aliméntaria i els orígens de l'agricultura: una perspectiva caçadora-recolectora". En J. Anfruns y E. Lloret (eds.): El Canvi Cultural a la Prehistoria. Columna. Barcelona:197-220.

Godelier, M. (1989): Lo ideal y lo material. Pensamiento, economías, sociedades. Taurus. Barcelona.

- (1998): "Funciones, formas y figuras del poder político". Congreso Internacional: Los Iberos, Príncipes de Occidente. SAGVNTVM-PLAV, Extra-1: 13-21.

Gómez Barrera, J.A. (1982): La Pintura Rupestre Esquemática en la Altimeseta Soriana. Ayuntamiento de Soria. Soria.

- (2001): Ensayos sobre el significado y la interpretación de las pinturas rupestres de Valonsadero. Ed. Diputación Provincial de Soria. Soria.

Gordon Childe, V. (1935): "Changing Methods and Aims in Prehistory. Presidencial address for 1935". Proceedings of the Prehistoric Society I: 1-15.

G.R.A.P.P. (1993): L'art pariétal paléolithique. Técniques et méthodes d'etude. Ed. du Comité des Travaux Historiques et Scientifiques. Documents Préhistoriques 5. París.

Hernández Pacheco, E. (1959): Prehistoria del solar hispano. Orígenes del arte pictórico. Real Academia de Ciencias Exactas, Físicas y Naturales XX, Madrid.

Hernández Pérez, M.S.; Ferrer, P. y Catalá, E. (1988): Arte rupestre en Alicante. Fundación Banco Exterior y Banco de Alicante. Alicante.

Hernando Gonzalo, A. (1999): "El espacio no es necesariamente un lugar: en torno al concepto de espacio y sus implicaciones en el estudio de la prehistoria". Arqueología Espacial 21: 7-27.
Hodder, I. (1982a): Symbols in Action . Cambridge University Press. Cambridge.

- (1982b): "Sequences of Structural Change in the Dutch Neolithic". En I. Hodder (ed.): Symbolic and Structural Archaeology. Cambridge University Press. Cambridge.

JAMENSON, F. (1981): The Political Unconscious. Narrative as a Socially Symbolic Act. Methuen. London.

LAMING-EMPERAIRE, A. (1962): La signification de l'art rupestre paléolithique. Methodes et applications. Picard. París.

- (1972): "Art rupestre et organisation sociale". Actas Simposium Internacional de Arte Prehistórico (Santander 1970): 65-79. Madrid.

León GiL, M. (1988): "Pinturas rupestres esquemáticas de la Sierra del Conde. Oliva de Mérida (Badajoz)". Proserpina 7: 7-31.

León Gil, M. y García-Verdugo Rubio, R. (1986): Pintura rupestre esquemática en Mérida, Sierra de Arroyo de San Serván. Caja de Ahorros de Badajoz. Badajoz.

LEROI-GourhAN, A. (1958): "Répartition et groupement des animaux dans l'art pariétal paléolithique". Bulletin de la Société Préhistorique Française 55, 9: 515-528.

- (1965): Préhistoire de l'art occidental. Mazenod. París.

- (1972): "Considerations sur l'organisation spatiale des figures animales, dans l'art parietal paléolithique". Actas Simposium Internacional de Arte Prehistórico (Santander 1970): 281-308. Madrid.

Levi-Strauss, C. (1958): Anthropologie Structurale. Librairie Plon. París.

- (1963): Tristes Tropiques. Atheneum. New York.

Lewis-Williams, D. y Blundell, G. (1998): Fragile Heritage. A Rock Art Fieldguide. Witwatersrand University Press. Johannesburg.

López Payer, M.G. y Soria Lerma, M. (1988): El arte rupestre en Sierra Morena Oriental. Ed. López y Soria. La Carolina, Jaén.

MaLinowsky, B. (1972): "The problem of meaning in primitive language". En C. K. Ogden e I. A. Richards, The meaning of meaning. En C.K. Ogden e I.A. Richards (eds.): The meaning of meaning: a Study of the Influence of Language upon Thought and of the Science of Symbolism. Routledge \& Kegan Paul, Ltd. Londres.

Martín de GuZmán, C. (1983): "Las dificultades del 'discurso' esquemático". Zephyrus XXXVI, Actas Coloquio Internacional de Arte Esquemático (Salamanca 1982): 209-216.

Martínez García, J. (1981): "El conjunto rupestre de la Rambla de Gérgal (Gérgal, Almería). Nuevos descubrimientos y apreciaciones cronológicas". Cuadernos de Prehistoria de la Universidad de Granada 6: 35-70.

- (1984): "El Peñón de la Virgen: Un conjunto de pinturas rupestres en Gilma (Nacimiento, Almería). Asociaciones recurrentes, simbolismo y modelo de distribu-

T. P., 59, n. ${ }^{\circ} 1,2002$ 
ción". Cuadernos de Prehistoria de la Universidad de Granada 9: 39-84.

- (1988): "Análisis de un sistema de parentesco en las pinturas rupestres de la Cueva de Los Letreros (VélezBlanco, Almería)". Ars Praehistórica 7-8, Homenaje E. Ripoll 1988-1989, Sabadell:183-193.

- (1998): “Abrigos y accidentes geográficos como categorías de análisis en el paisaje de la pintura rupestre esquemática. El sudeste como marco". Arqueología Espacial 19-20: 543-561.

- (2000): "La pintura rupestre esquemàtica com a estratègia simbòlica d'ocupació territorial". Cota Zero 16: $35-46$.

Martínez Perelló, M.I. y Díaz-Andreu, M. (1992): “El abrigo pintado de Hoz de Vicente (Minglanilla, Cuenca)". Espacio, Tiempo y Forma, Prehistoria y Arqueología 5: 241-268.

Mathers, C. (1984): "Linnear regression, onflation and prestige competition: 2 nd millenium transformations in South East Spain". B.A.R. International Series, 229 IV. Oxford: 1167-1196.

Piñón VAREla, F. (1982): Las pinturas rupestres de Albarracín (Teruel). Centro de Investigación y Museo de Altamira. Monografía 6. Santander.

Priego Fernández del CAmpo, C. (1991): "Pintura rupestre del Abrigo de los Aljibes en la Pedriza del Manzanares”. Estudios de Prehistoria y Arqueología Madrileña: 95-129.

Raphael, M. (1945): Prehistoric Cave Painting. Bollingen Series IV. New York.

Rivero de la Higuera, M.C. (1972-73): "Nuevas estaciones de pinturas rupestre esquemática en Extremadura". Zephyrus XXIII-XXIV: 287-308.

SAHLinS, M.D. (1972): Las sociedades tribales. Ed. Labor S.A. Barcelona.

Santos Estévez, M. (1998): "Los espacios del arte: el diseño del panel y la articulación del paisaje en el arte rupestre gallego". Trabajos de Prehistoria 55 (2): 73-88.
Santos Estévez, M. y CRiado Boado, F. (1998): "Espacios rupestres: del panel al paisaje". Arqueología Espacial 19-20: 579-596.

SAuvet, G. y WlodarczyK, A. (1977): "Essai de semiologie préhistorique (Pour une theorie des premiers signes graphique de l'homme)". Bulletin Société Préhistorique Française 74, 2: 545-558.

SCHUSTER, C. (1958): "Some 'Geometric' desings of upper paleolithic art". Fifth International Congress of Preand Protohistory. Hamburg.

SMith, C. (1991): "Female Artists: the Unrecognized Factor in Sacred Rock Art Production". En P. Bahn y A. Rosenfeld (eds.): Rock Art and Prehistory. Oxbow books. Oxford: 45-52.

Solomon, A. (1997): "El arte rupestre del Africa meridional". Investigación y Ciencia, enero: 74-83.

SPERBER, D. (1978): El simbolismo en general. Anthropos Editorial del Hombre. Barcelona.

Turner, V. (1974): Dramas, Fields and Metaphors: Symbolic Action in Human Society. Cornell University Press. Ithaca.

Vicent García, J.M. (1991): "El neolítico. Transformaciones sociales y económicas". Boletín Antropología Americana 24: 31-62.

Wagner, R. (1967): The curse of Souw: Principles of Daribi clan definition and alliance. University of Chicago Press. Chicago.

WASHBURN, D.K. (ed.) (1983): Structure and cognition in art. New Directions in Archaeology. Cambridge University Press. Cambridge.

WATCHMAN, A.L. y LESSARD, R. (1993): "Focused laser extration of carbonaceous substances for AMS radiocarbon dating (FLESCS-AMS)". Time and Space. AURA, 8. Ed. Steinbring, Watchman, Faulstich y Taçon. Melbourne: 74-77.

Wolf, E.R. (1987): Europa y la gente sin historia. Fondo de Cultura Económica. México. $1^{\text {a }}$ ed. en inglés 1982. 